\title{
Synaptotagmin 1 directs repetitive release by coupling vesicle exocytosis to the Rab3 cycle
}

\section{Yunsheng Cheng ${ }^{1,2 \dagger}$, Jiaming Wang ${ }^{1,2 \dagger}$, Yu Wang ${ }^{1,2}$, Mei Ding ${ }^{1,3 *}$}

${ }^{1}$ State Key Laboratory of Molecular Developmental Biology, Institute of Genetics and Developmental Biology, Chinese Academy of Sciences, Beijing, China; ${ }^{2}$ University of Chinese Academy of Sciences, Beijing, China; ${ }^{3}$ Center for Excellence in Brain Science, Chinese Academy of Sciences, Shanghai, China

Abstract In response to $\mathrm{Ca}^{2+}$ influx, a synapse needs to release neurotransmitters quickly while immediately preparing for repeat firing. How this harmonization is achieved is not known. In this study, we found that the $\mathrm{Ca}^{2+}$ sensor synaptotagmin 1 orchestrates the membrane association/disassociation cycle of Rab3, which functions in activity-dependent recruitment of synaptic vesicles. In the absence of $\mathrm{Ca}^{2+}$, synaptotagmin 1 binds to Rab3 GTPase activating protein (GAP) and inhibits the GTP hydrolysis of Rab3 protein. Rab3 GAP resides on synaptic vesicles, and synaptotagmin 1 is essential for the synaptic localization of Rab3 GAP. In the presence of $\mathrm{Ca}^{2+}$, synaptotagmin 1 releases Rab3 GAP and promotes membrane disassociation of Rab3. Without synaptotagmin 1, the tight coupling between vesicle exocytosis and Rab3 membrane disassociation is disrupted. We uncovered the long-sought molecular apparatus linking vesicle exocytosis to Rab3 cycling and we also revealed the important function of synaptotagmin 1 in repetitive synaptic vesicle release.

DOI: 10.7554/eLife.05118.001

\section{Introduction}

In nerve terminals, neurotransmitters are packaged into synaptic vesicles (SVs) and released by $\mathrm{Ca}^{2+}$-induced exocytosis (Sudhof, 2004). Fast and precise neuronal reaction requires that SVs are clustered in front of the release site, the presynaptic active zone. SVs then dock at the active zone, where they are primed to adopt a competent "ready-for-fusion" state. An action potential induces the opening of $\mathrm{Ca}^{2+}$ channels, and the rising $\mathrm{Ca}^{2+}$ concentration stimulates SV-plasma membrane fusion. The basic membrane fusion reaction is mediated by evolutionarily conserved soluble NSF attachment protein receptors (SNAREs) and related proteins like Munc13 and Munc18 (Weber et al., 1998; Sudhof, 2004; Brunger, 2005; Jahn and Scheller, 2006; Lang and Jahn, 2008; Jahn and Fasshauer, 2012). However, the $\mathrm{Ca}^{2+}$-sensing process that starts the SNARE engine is primarily carried out by the synaptotagmin family (Chapman, 2002; Jahn and Fasshauer, 2012). Through their $\mathrm{C} 2$ domains, synaptotagmins bind to $\mathrm{Ca}^{2+}$, thus triggering membrane fusion (Sudhof, 2004). After exocytosis, SVs undergo endocytosis and recycling and are refilled with neurotransmitters for repeated rounds of release.

Rab3 protein is highly enriched in the nervous system and is specifically localized on SVs (Fischer von Mollard et al., 1991; Fischer von Mollard et al., 1994; Geppert et al., 1994; Stahl et al., 1996). Like other Rabs, Rab3 cycles on and off its target membranes according to its GTP- or GDP-bound state. On the vesicles, the active GTP-bound form of Rab3 is complexed with effector proteins like rabphilin and RIM (Rab3-interacting molecule) (Shirataki et al., 1993; Li et al., 1994; Wang et al., 1997, 2000), thus facilitating the recruitment/docking of SVs (Nonet et al., 1997; Leenders et al., 2001; Tsuboi and Fukuda, 2006). $\mathrm{Ca}^{2+}$-induced exocytosis 
eLife digest Neurons communicate with one another at junctions called synapses. The arrival of an electrical signal called an action potential causes calcium ions to enter the first cell, which in turn triggers the release of molecules called neurotransmitters into the gap between the neurons. The binding of these molecules to receptors on the second cell then enables the action potential to be regenerated.

For cells to respond rapidly and reliably to incoming electrical signals, they must maintain a supply of vesicles-the packages that contain neurotransmitters-close to the site where they are released from the first cell. The vesicles are held in contact with the cell membrane by a structure called the docking complex. A number of the proteins in this docking complex have been identified, including two that have been referred to as the 'yin and yang' of vesicle fusion: synaptotagmin, which promotes fusion, and Rab3, which limits it. However, little is known about how these and other proteins interact to keep vesicles docked at the membrane.

Cheng, Wang et al. have now clarified the docking process with the aid of experiments in nematode worms. In resting neurons that are not releasing neurotransmitters, synaptotagmin ('yin') binds to an enzyme called GAP and prevents it from converting GTP-an energy-storage molecule-into GDP. Given that Rab3 ('yang') requires a molecule of GTP to power its own activity, the actions of synaptotagmin ensure that Rab3 has enough energy to remain bound to other proteins within the docking complex.

However, when an action potential arrives, calcium ions enter the neuron, and some of them bind to synaptotagmin. This disrupts its interaction with the GAP enzyme, which thus becomes free to convert the GTP molecule bound to Rab3 into GDP. The loss of its energy source causes Rab3 to separate from its binding partners, and docking complex collapses. As a result, vesicles fuse with the membrane and release neurotransmitter molecules into the synapse.

Given that Rab3 and synaptotagmin have changed little over the course of evolution, it is highly likely that the same indirect interaction between these two proteins also regulates the release of transmitter at synapses in the mammalian brain.

DOI: 10.7554/eLife.05118.002

can trigger disassociation of Rab3 from SV membranes through the GTP hydrolysis process (Fischer von Mollard et al., 1991; Fischer von Mollard et al., 1994; Stahl et al., 1996), but the underlying mechanisms are not clear. The GTP-to-GDP conversion not only removes Rab3 from $\mathrm{SV}$, but also simultaneously dissociates Rab3 from its binding effectors, which disassembles the docking complex so that both Rab3 and Rab3 effectors can be recycled for the next round of release (Wang et al., 1997, 2000). Given their unique features, Rab3 and synaptotagmin have been considered as the Yin and Yang of membrane fusion, respectively (Geppert and Südhof, 1998). However, the functional regulatory interaction between synaptotagmin 1 and Rab3 cycling has not been identified nor has the mechanism by which this interaction is coupled to fast and repetitive neurotransmitter release.

Here, we found that synaptotagmin 1/SNT-1 in C. elegans is crucial for the SV association of RAB-3 protein. SNT-1 promotes the GTP-bound state of RAB-3 by inhibiting RAB-3 GAP. The catalytic subunit of RAB-3 GAP (RBG-1) localizes on SVs and directly binds to SNT-1. Ca ${ }^{2+}$ treatment disrupts the direct association between SNT-1 and RBG-1. In addition, $\mathrm{Ca}^{2+}$-binding activity of SNT-1 is essential for the dissociation of RAB-3 from SVs. Thus, our study reveals the pivotal dual role of synaptotagmin 1 in coupling SV exocytosis with the Rab3 membrane association and dissociation cycle.

\section{Results}

\section{Search for components involved in RAB-3/SV association}

In C. elegans motor neurons, RAB-3 fused with Green Fluorescent Protein (GFP) adopts a punctate pattern of localization along the length of the ventral and dorsal cords (Mahoney et al., 2006). This punctate RAB-3 pattern is similar to that of other SV proteins, including synaptobrevin and synaptotagmin (Nonet et al., 1993; Nonet, 1999; Zhen and Jin, 1999). A previous report also 
A
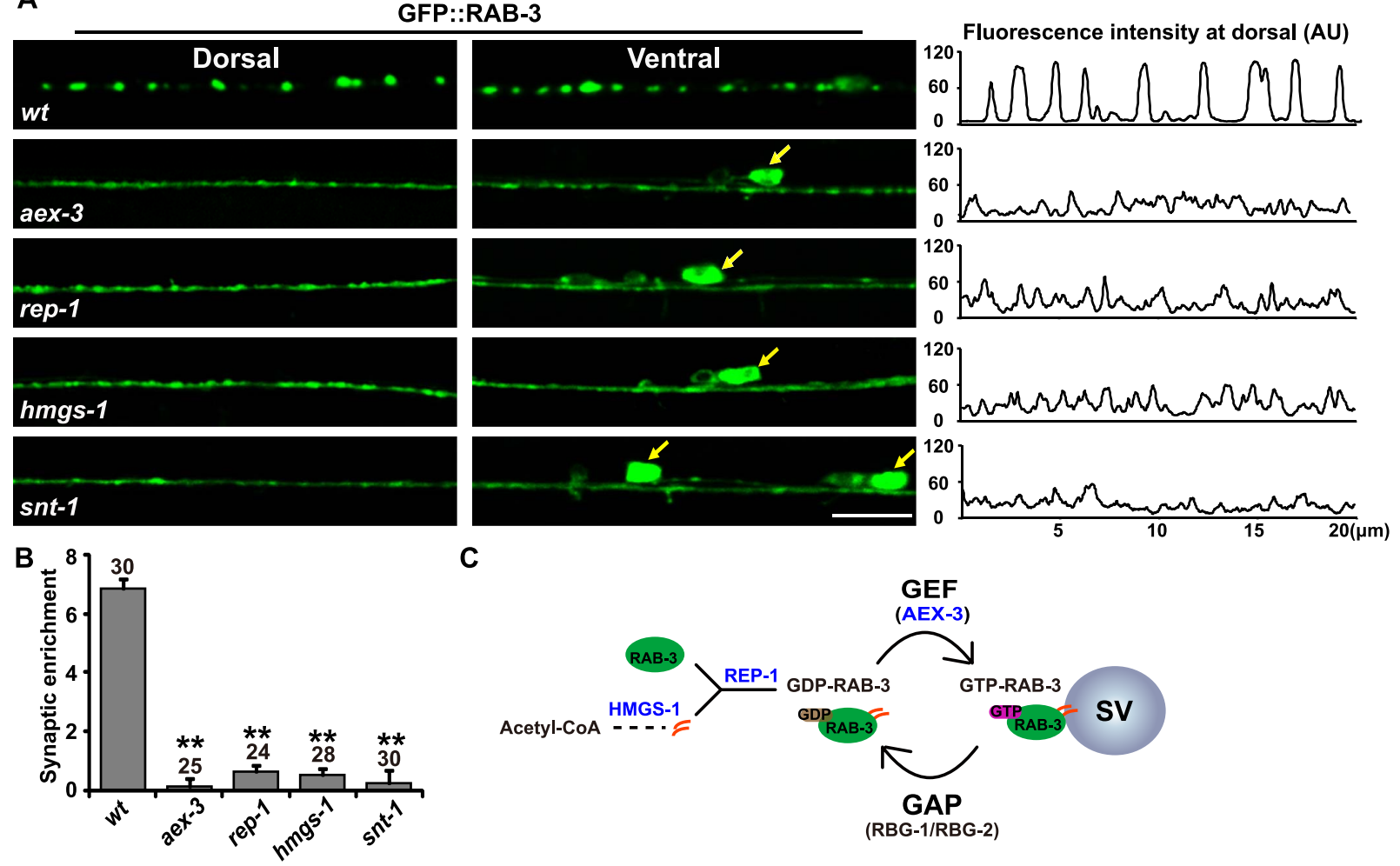

C

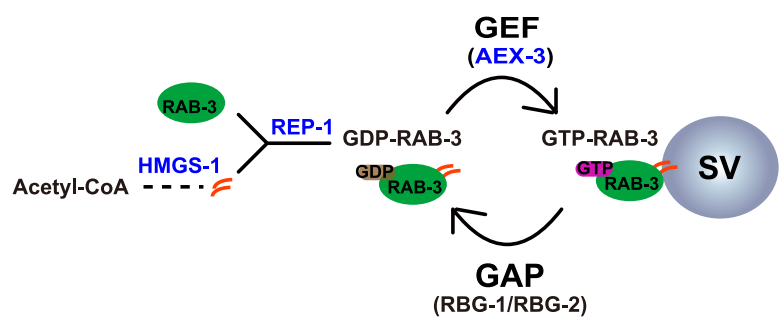

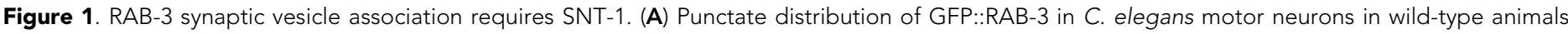

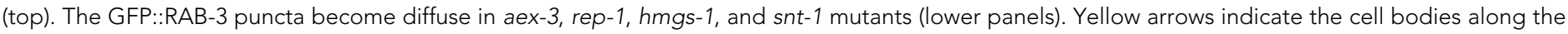

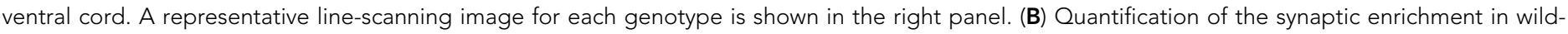

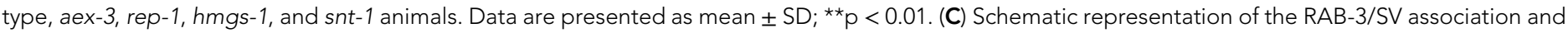
dissociation cycle. Scale bar, $5 \mu \mathrm{m}$.

DOI: 10.7554/eLife.05118.003

The following figure supplement is available for figure 1:

Figure supplement 1. snt-1 is require for RAB-3 synaptic vesicle localization.

DOI: 10.7554/eLife.05118.004

showed that most Rab3 protein is associated with SV membranes (Fischer von Mollard et al., 1990). In the absence of the RAB-3 GEF, AEX-3 (Iwasaki et al., 1997), GFP::RAB-3 no longer shows a punctate pattern and becomes diffusely distributed in neuron cell bodies and axons (Figure 1A). AEX-3 is responsible for converting RAB-3 protein from the membrane-dissociated GDP-bound form to the membrane-associated GTP-bound form (Figure 1C). Therefore, the punctate localization of RAB-3 in wild type likely represents the GTP-bound, SV membrane-associated form of RAB-3, while the diffuse GFP::RAB-3 signal may represent the dissociated GDP-RAB-3.

We speculated that mutations in components required for Rab3/SV association may lead to a diffuse RAB-3::GFP phenotype similar to that in aex-3 animals. Hence, we conducted a genetic screen and isolated multiple mutants in which GFP::RAB-3 lost its punctate localization pattern. Through SNP mapping, complementation testing, and fosmid rescue, we cloned all of these mutations. Six of them ( $x d 58, x d 137, x d 142, x d 143, x d 148$, and $x d 149)$ turned out to be new alleles of aex-3. In addition, we obtained four rep-1 alleles ( $x d 56, x d 138, x d 139$, and xd140) and three hmgs-1 alleles ( $x d 128, x d 129$, and $x d 145$ ). rep-1 encodes the sole Rab escort protein (Rep) (Tanaka et al., 2008). Rep proteins bind newly synthesized Rab proteins and facilitate the addition of geranylgeranyl groups to Rabs (Seabra et al., 1992a, 1992b; Andres et al., 1993) (Figure 1C). HMGS-1 is orthologous to the human hydroxymethylglutaryl-CoA synthase (HMGS) which is required for synthesis of the geranylgeranyl moiety (Mehrabian et al., 1986; Shi and Ruvkun, 2012) (Figure 1C). Thus, both rep-1 and hmgs- 1 are critical for RAB-3 membrane targeting. The diffuse GFP::RAB-3 phenotype in 
rep-1 and hmgs-1 mutants further suggested that the diffuse signal indeed comes from membranedissociated RAB-3 protein.

\section{Synaptotagmin/SNT-1 is required for localization of RAB-3 on SVs}

In the meantime, we hypothesized that the molecules controlling the RAB-3 cycle may be associated with SV cycling. Thus, we systematically examined SV cycle-related mutants. Interestingly, we found that in snt-1(md290) animals, which lack snt-1 function, the GFP::RAB-3 puncta disappeared and the GFP signal was diffusely distributed throughout the neuronal processes, similar to aex-3, rep-1, and hmgs-1 mutants (Figure 1A,B). The strong phenotypic similarity between snt-1 and other RAB-3/SV-association defective mutants suggests that SNT-1 plays an important role in RAB-3/SV localization.

snt-1 encodes the synaptotagmin 1 homologue in C. elegans (Nonet et al., 1993). Neuronal synaptotagmins function as $\mathrm{Ca}^{2+}$ sensors for synaptic exocytosis, but their role in Rab3 localization has not been revealed. To determine whether loss of snt- 1 function indeed leads to the diffuse RAB-3 phenotype, we examined other snt- 1 alleles. We found that the $n 2665$, md220, md125, and md172 alleles of snt-1 all display a diffuse GFP::RAB-3 phenotype similar to md290 (Figure 1-figure supplement 1A). Both the snt-1 and rab-3 genes are broadly expressed in the nervous system (Nonet et al., 1993, 1997). To determine whether snt-1 influences RAB-3 in all neurons, we examined RAB-3 localization with a pan-neuronal marker Prab-3::GFP::RAB-3. In wild-type animals, GFP::RAB-3 displays a punctate pattern, while in snt-1 mutants, GFP::RAB-3 is completely diffuse in neuronal processes, including the nerve ring, ventral cord, and dorsal cord regions (Figure 1-figure supplement $1 B, C$. These data indicate that the effect of snt-1 on RAB-3 localization is widely preserved in the nervous system. In addition, the diffuse GFP::RAB-3 phenotype was fully rescued when wild-type snt-1 was introduced into mutant animals (Figure 1-figure supplement 1D), suggesting that SNT-1 is indeed essential for localization of RAB-3 on SVs.

\section{snt-1 affects RAB-3 localization through an SV-independent mechanism}

The diffuse RAB-3 phenotype in snt-1 may be caused by failure of SV clustering at the synaptic terminal. Therefore, we examined the localization of another synaptic vesicle protein SNB-1. SNB-1 is the C. elegans synaptobrevin homologue (Nonet, 1999). In worm DD and VD motor neurons, SNB-1 is distributed evenly in punctate structures along neuronal processes, similar to RAB-3 (Figure 2A) (Zhen and Jin, 1999). In snt-1 animals, some of the SNB-1 puncta are enlarged, but the punctate distribution of SNB-1 is not altered (Figure 2A,B). This observation is consistent with recent findings (Yu et al., 2013), suggesting that SV clustering is probably not affected by snt-1.

unc-104 encodes the cytosolic kinesin responsible for synaptic vesicle trafficking from cell bodies to nerve terminals (Hall and Hedgecock, 1991). In the absence of UNC-104 kinesin, few SVs are transported to synaptic termini, while neuron cell bodies have a surfeit of SVs. To further address whether the diffuse RAB-3 phenotype is indeed caused by the dissociation of RAB-3 from SVs in snt-1 mutants, we performed a serial mutant analysis utilizing both GFP::RAB-3 and SNB-1::GFP markers. Because the snt-1;unc-104 double mutant animals are arrested during larval development, the synaptic phenotypes were examined in newly hatched L1 animals (larval stage 1). In L1 animals, among DD, VD, and AS motor neurons, only DDs are born (Sulston, 1976; Sulston and Horvitz, 1977), and they form pre-synapses along the ventral cord. Thus, in wild-type L1 animals labeled by Punc-25::SNB-1::GFP, the GFP signal could only be detected along the ventral cord (Figure 2C, $C^{\prime \prime}$ ) but not the dorsal cord (Figure 2C'). In snt-1 mutants, the SNB-1::GFP distribution is indistinguishable from wild type (Figure 2D, $D^{\prime}$, and 2D"). In unc-104 single mutants, we found that SNB-1::GFP accumulated in cell bodies (Figure 2E,E", white arrow) and little GFP signal could be detected outside of cell bodies or on the dorsal cord (Figure 2E'), which is consistent with the role of UNC-104 in SV transport. In snt-1;unc-104 double mutants, the SNB-1::GFP signal accumulated in cell bodies (Figure 2F, $F^{\prime \prime}$, white arrow) like in unc-104 single mutants, suggesting that further removal of SNT-1 in unc-104 mutant animals does not alter the dependence of SVs on UNC-104 for intracellular trafficking. Interestingly, the effect of snt-1 or snt-1 unc-104 mutations on RAB-3 and SNB-1 is quite different. As shown in Figure 2H,J, GFP::RAB-3 is still diffuse in cell bodies and axons in both snt-1 and snt-1 unc-104 animals, and GFP signal could be detected even in the non-synaptic dorsal cord region (Figure $2 \mathrm{H}^{\prime}$ and $2 \mathrm{~J}$ ). In contrast, in unc-104 animals, the RAB-3 puncta are retained within cell bodies, just like SNB-1 is in unc-104 mutants (Figure 2I,I'). These data strongly 


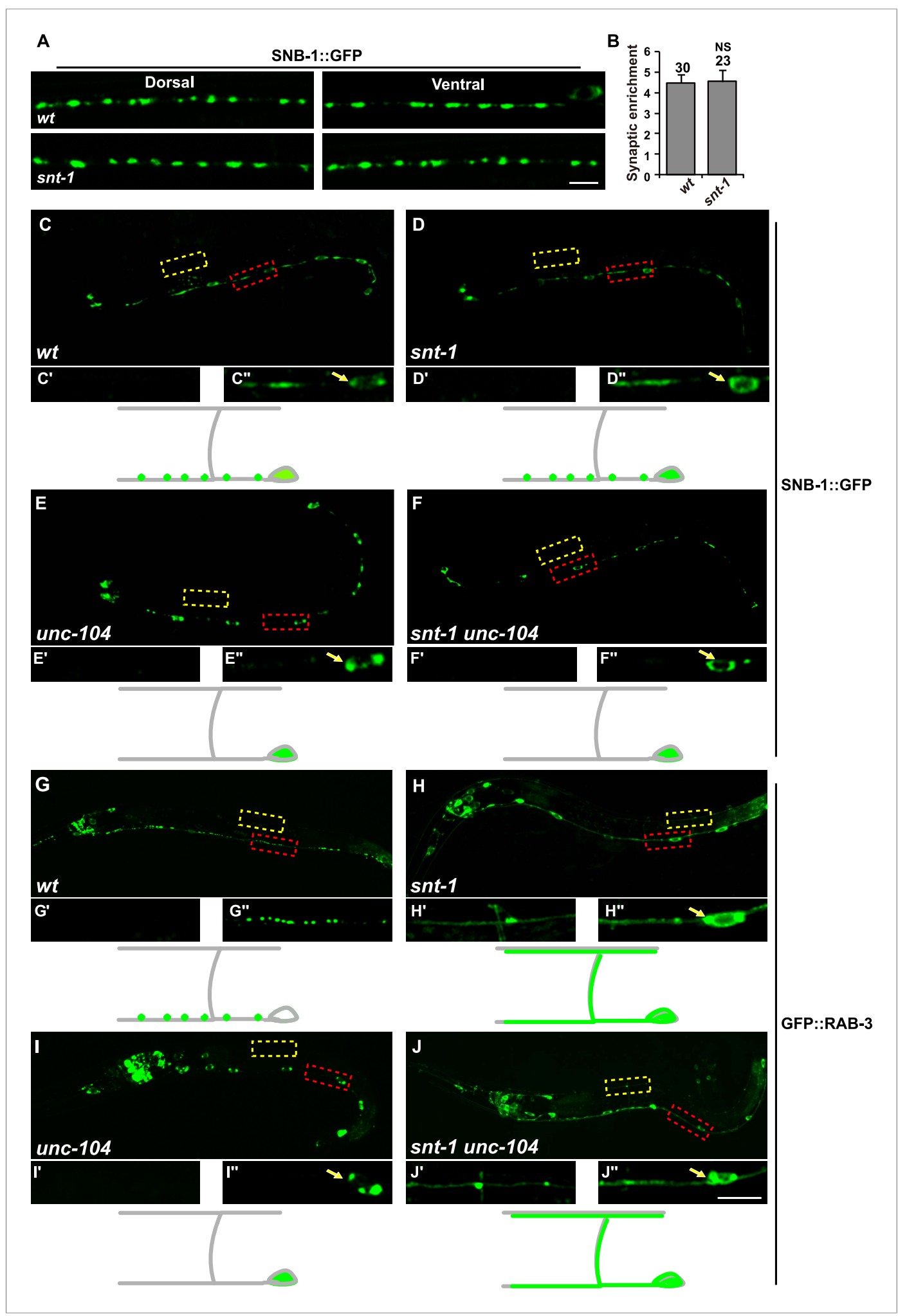

Figure 2. Synaptic vesicle clustering is unaffected by loss of snt-1 function. (A) SNB-1::GFP puncta distribution in wild type and snt-1 mutants. (B) The synaptic enrichment of SNB-1::GFP puncta is indistinguishable in wild type and snt-1. Data are presented as mean \pm SD; NS, not significant. In both wild type $\left(\mathbf{C}, \mathbf{C}^{\prime}\right.$ and $\left.\mathbf{C}^{\prime \prime}\right)$ and snt-1 (D, $\mathbf{D}^{\prime}$ and $\mathbf{D}^{\prime \prime}$ ), the SNB-1::GFP puncta are present in the synaptic area on the ventral cord, which is outside of the cell body $\left(\mathbf{C}^{\prime \prime}\right.$ and $\left.\mathbf{D}^{\prime \prime}\right)$. In unc-104 (E, $\mathbf{E}^{\prime}$ and $\left.\mathbf{E}^{\prime \prime}\right)$ or snt-1 unc-104 double mutants $\left(\mathbf{F}, \mathbf{F}^{\prime}\right.$ and $\left.\mathbf{F}^{\prime \prime}\right)$, SNB-1::GFP accumulates in the cell bodies on the ventral cord $\left(\mathbf{E}^{\prime \prime}\right.$ and $\left.\mathbf{F}^{\prime \prime}\right)$. (G) In wild type, GFP::RAB-3 is distributed in a punctate pattern in the Figure 2. continued on next page 
Figure 2. Continued

pre-synaptic regions on the ventral cord (G"). (H) GFP::RAB-3 is diffuse throughout the whole axon including both dorsal $\left(\mathbf{H}^{\prime}\right)$ and ventral $\left(\mathbf{H}^{\prime \prime}\right)$ processes. (I) GFP::RAB-3 accumulates in ventral cell bodies $\left(\mathbf{I}^{\prime \prime}\right)$. (J) In snt-1 unc-104 double mutants, GFP::RAB-3 is diffuse throughout the whole axon in both dorsal $\left(\mathbf{J}^{\prime}\right)$ and ventral $\left(\mathbf{J}^{\prime \prime}\right)$ regions. Yellow boxes indicate part of the dorsal cord, which is enlarged in the lower left panels. Red boxes indicate part of the ventral cord, which is enlarged in the lower right panels (white arrows indicate DD cell bodies in the ventral cord). A schematic drawing of a DD neuron during the L1 stage is presented underneath the fluorescence images of each genotype, with the SNB-1::GFP or GFP::RAB-3 signal shown in green. Small green dots represent the pre-synaptic areas. Individual DD cell bodies are indicated as large ovals at the bottom right of each diagram. Scale bars, $5 \mu \mathrm{m}$. DOI: 10.7554/eLife.05118.005

support the notion that the diffuse phenotype of RAB-3 is not caused by the dispersion of SV clusters, but rather by the specific dissociation of RAB-3 from SV membranes.

\section{SNT-1 promotes the GTP-bound form of RAB-3}

How does mutation of snt-1 affect the SV membrane association of RAB-3? Previous studies showed that the localization of RAB-3 on SV membranes is tightly associated with its GTP-bound state (Zerial and McBride, 2001). Therefore, we tested whether the loss of RAB-3 from SVs in snt-1 mutants is caused by reduction of GTP-bound RAB-3. The active GTP-Rab3 binds to the RBD domain of its effector RIM, while the inactive GDP-Rab3 does not. Previous reports demonstrated that the RBD domain of mammalian RIM2 could bind to the worm GTP-RAB-3 (Wang et al., 1997; Mahoney et al., 2006). Thus, we performed pull-down assays to examine the GTP-RAB-3 level in vivo. In wild-type worm lysates, the active GTP-bound form of RAB-3 protein was efficiently pulled down by GST-RBD (Figure 3A). In contrast, the amount of GTP-RAB-3 pulled down by RIM2 RBD was significantly reduced in snt-1 lysates (Figure $3 A, B$ ). In the absence of RAB-3 GEF, the GDP-bound RAB-3 cannot be converted to the GTP-bound RAB-3. Indeed, in aex-3 animals, the amount of RAB-3 that can be pulled down by GST-RBD is also greatly decreased (Figure $3 A, B$ ). Thus snt-1, similar to aex-3, affects the level of GTP-bound RAB-3 in vivo.

GTP-RAB-3 is associated with SV membranes, while GDP-RAB-3 is diffused in the cytosol. Thus, we performed cell fractionation experiments to further examine the GTP or GDP status of RAB-3. In wild type, RAB-3 is highly enriched in membrane fractions (Figure $3 C$ ), which is consistent with the SV localization of GTP-RAB-3. In contrast, the RAB-3 protein distribution is shifted to the soluble fraction when snt-1 is removed, suggesting a cytosolic localization of RAB-3 in snt-1 mutants (Figure 3C). These data suggest that snt-1 indeed promotes the GTP-bound form of RAB-3.

\section{SNT-1 promotes the GTP-RAB-3 level by inhibiting GTP hydrolysis}

How does loss of function of snt-1 lead to the reduction of GTP RAB-3? One possibility is that SNT-1 may regulate the RAB-3 GTP-GDP cycle by promoting GEF activity. We performed the following experiments to test this possibility. Firstly, AEX-3 is the GEF molecule for both RAB-3 and RAB-27 (Mahoney et al., 2006). If snt-1 indeed affects AEX-3 activity, we would expect that the localization of RAB-27 on SVs will be affected by the absence of SNT-1. We made a GFP::RAB-27 reporter and expressed it in motor neurons in worms. The GFP::RAB-27 protein is enriched in synaptic regions and displays a punctate expression pattern similar to RAB-3 (Figure 3D). In aex-3 mutants, GFP::RAB-27 becomes diffuse, consistent with the role of AEX-3 as a GEF for RAB-27 (Figure 3D). In contrast, GFP::RAB-27 still displays a punctate distribution indistinguishable from wild type in snt-1 mutants (Figure 3D), suggesting that the GEF activity of AEX-3, at least for RAB-27, is not altered by mutation of snt-1. Second, if SNT-1 promotes AEX-3 GEF activity, we would expect that increasing the aex-3 expression level may rescue the diffuse RAB-3 phenotype in snt- 1 mutants. However, no such rescue was observed (Figure 3E). Lastly, we examined the expression level of AEX-3 and found that it was indistinguishable in wild-type and snt-1 animals (Figure 3F). Together, these results suggest that it is unlikely that snt-1 regulates the GTP-RAB-3 level by promoting RAB-3 GEF activity.

Alternatively, the decreased GTP-RAB-3 level may be caused by increased RAB-3 GTPase activity in snt-1 mutants. Rab3 GTPase activity is greatly facilitated by Rab3-specific GTPase-activating protein (GAP). Rab3 GAP is composed of the catalytic subunit Rab3GAP1 and the noncatalytic subunit Rab3GAP2. rbg-1 and rbg-2 encode Rab3GAP1 and Rab3GAP2, respectively in worms 


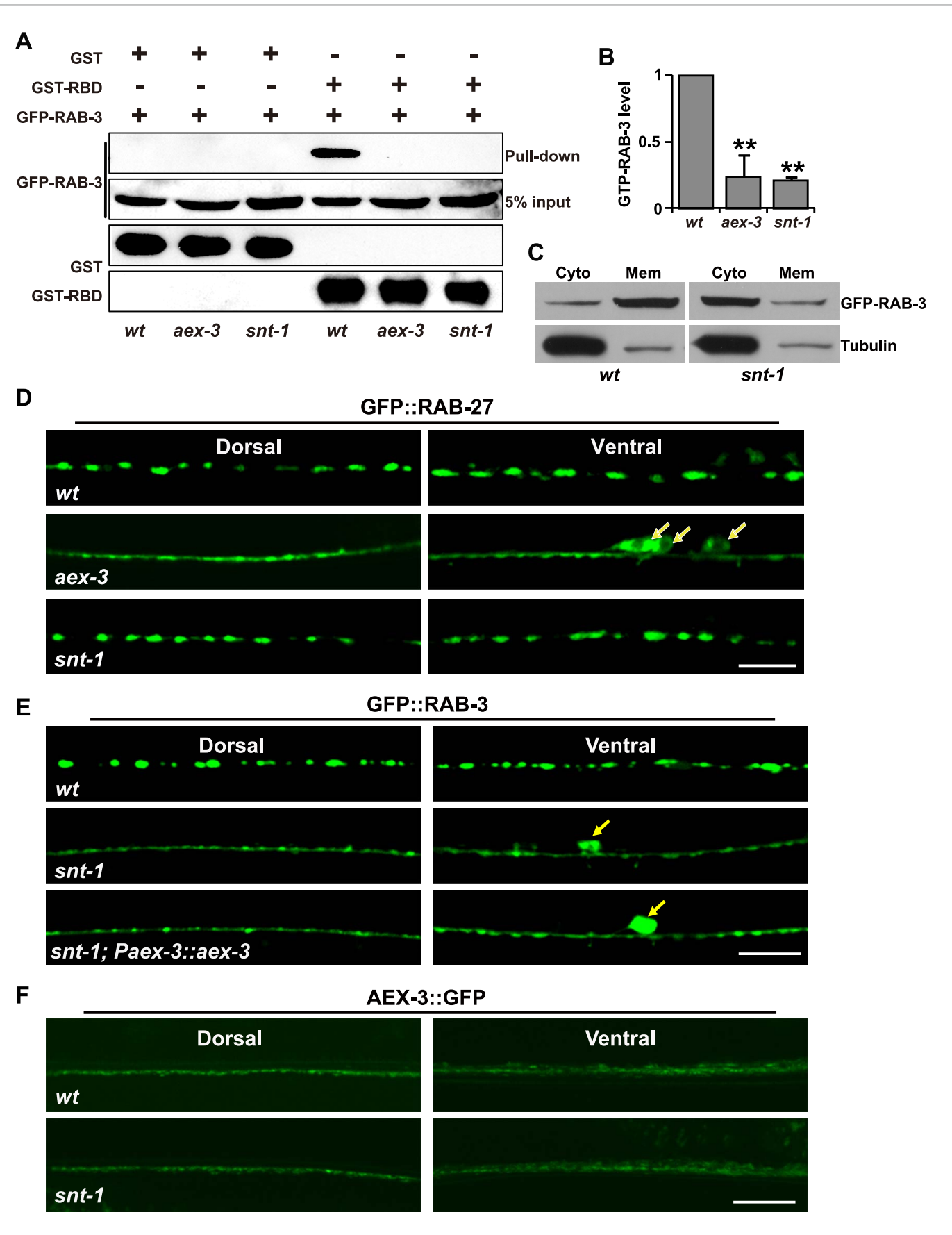

Figure 3. The GTP-bound form of RAB-3 is decreased in snt-1 mutants. (A) A GST-fused RBD domain of RIM2 binds active GTP-RAB-3. The amount of GTP-RAB-3 pulled down by RBD is decreased in both aex-3 and snt-1 animals. (B) Quantification of the GTP-RAB-3 level in wild type, aex-3, and snt-1. Data are presented as mean \pm SD; ${ }^{* *} p<0.01$. (C) The amount of GFP-RAB-3 in the cytosolic fraction is increased in snt-1 mutants. (D) Localization of GFP::RAB-27 puncta is affected by mutation of aex-3, but not by mutation of snt-1. The white arrows indicate the cell bodies. (E) Over-expression of aex-3 does not rescue the snt-1 mutant phenotype. Yellow arrows indicate the cell bodies. (F) The AEX-3::GFP level is unchanged in snt-1 mutants compared to wild type. Scale bars, $5 \mu \mathrm{m}$. DOI: 10.7554/eLife.05118.006

(Figure 4-figure supplement 1A,B) (Fukui et al., 1997; Nagano et al., 1998). In the absence of Rab3 GAP, the RAB-3 synaptic enrichment is enhanced, which is consistent with the role of Rab3 GAP in assisting GTP hydrolysis (Figure 4-figure supplement $1 C_{1} D$ ). If RAB-3 GTP hydrolysis 
A

GFP::RAB-3
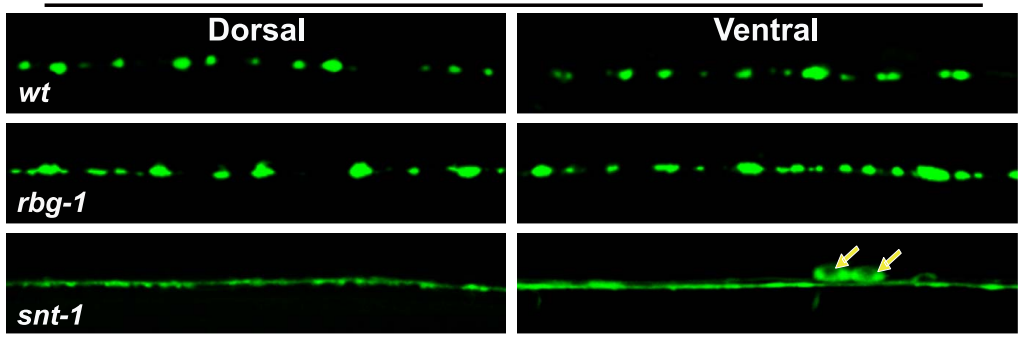

Fluorescence intensity at dorsal (AU)
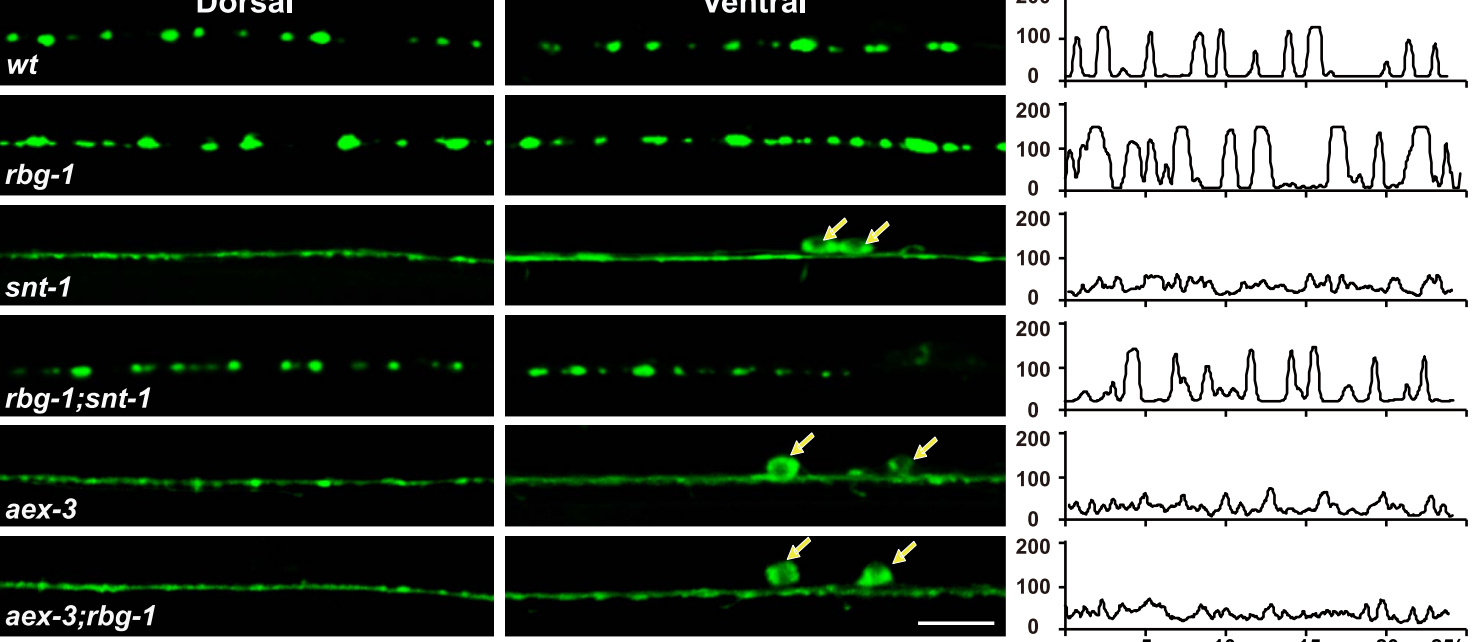

B
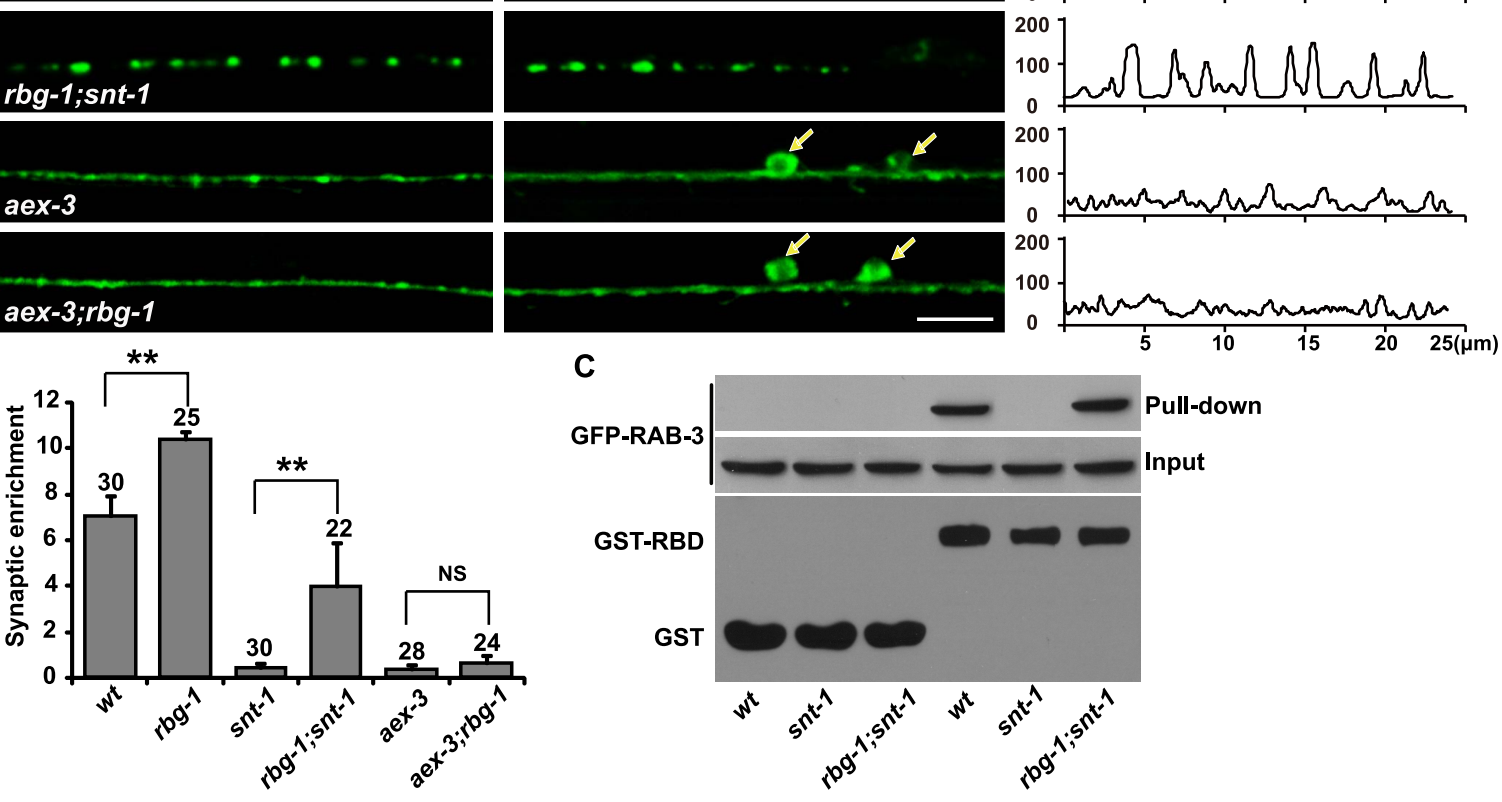

Figure 4. RAB-3 GAP mutations suppress the snt-1 mutant phenotype. (A) The punctate distribution of GFP::RAB-3 is restored in rbg-1;snt-1 animals, while the aex-3 phenotype could not be suppressed by mutation of rbg-1. Yellow arrows indicate the cell bodies along the ventral cord. Scale bar, $5 \mu$ m. A representative line-scanning image for each genotype is shown in the right panel. (B) Quantification of the synaptic enrichment of GFP.:RAB-3 signal in the genotypes shown in (A). Data are represented as mean \pm SD. ${ }^{\star *} p<0.01$; NS, not significant. (C) The amount of GTP-RAB-3 pulled down by RBD is increased in rbg-1;snt-1 animals compared to snt-1.

DOI: 10.7554/eLife.05118.007

The following figure supplement is available for figure 4:

Figure supplement 1. rbg-2 suppresses the snt-1 mutant phenotype. DOI: 10.7554/eLife.05118.008

activity is indeed increased in snt-1 mutants, we would expect that loss of GAP function will suppress the snt-1 mutant phenotype. Indeed, in rbg-1;snt-1 double mutants, we found that the diffuse GFP::RAB-3 phenotype of snt-1 single mutants is significantly suppressed (Figure 4A,B). Furthermore, mutation of the rbg-2 gene also suppressed the diffuse RAB-3 phenotype in snt-1 mutants (Figure 4-figure supplement 1E). In contrast, the diffuse GFP::RAB-3 signal caused by aex-3 mutation could not be suppressed by rbg-1 (Figure 4A,B). We next performed RIM2-RBD pull-down assays to test whether the GTP-RAB-3 level was restored in rbg-1;snt-1 mutants. In contrast to the greatly reduced GTP-RAB-3 level in snt- 1 lysates, the amount of GTP-bound RAB-3 is significantly increased in rbg-1; snt-1 samples (Figure 4C). Taken together, these results suggest that snt-1 indeed regulate the RAB-3/SV association specifically by inhibiting RAB-3 GTP hydrolysis.

\section{Rab3GAP1/RBG-1 localizes on SVs}

As the catalytic subunit of Rab3 GAP, RBG-1 can interact with RAB-3 (Figure 4-figure supplement 1F). To understand how SNT-1 inhibits RAB-3 GTP hydrolysis, we examined the sub-cellular localization of RBG-1. We created a functional mCherry::RBG-1 construct and injected it into rbg-1 


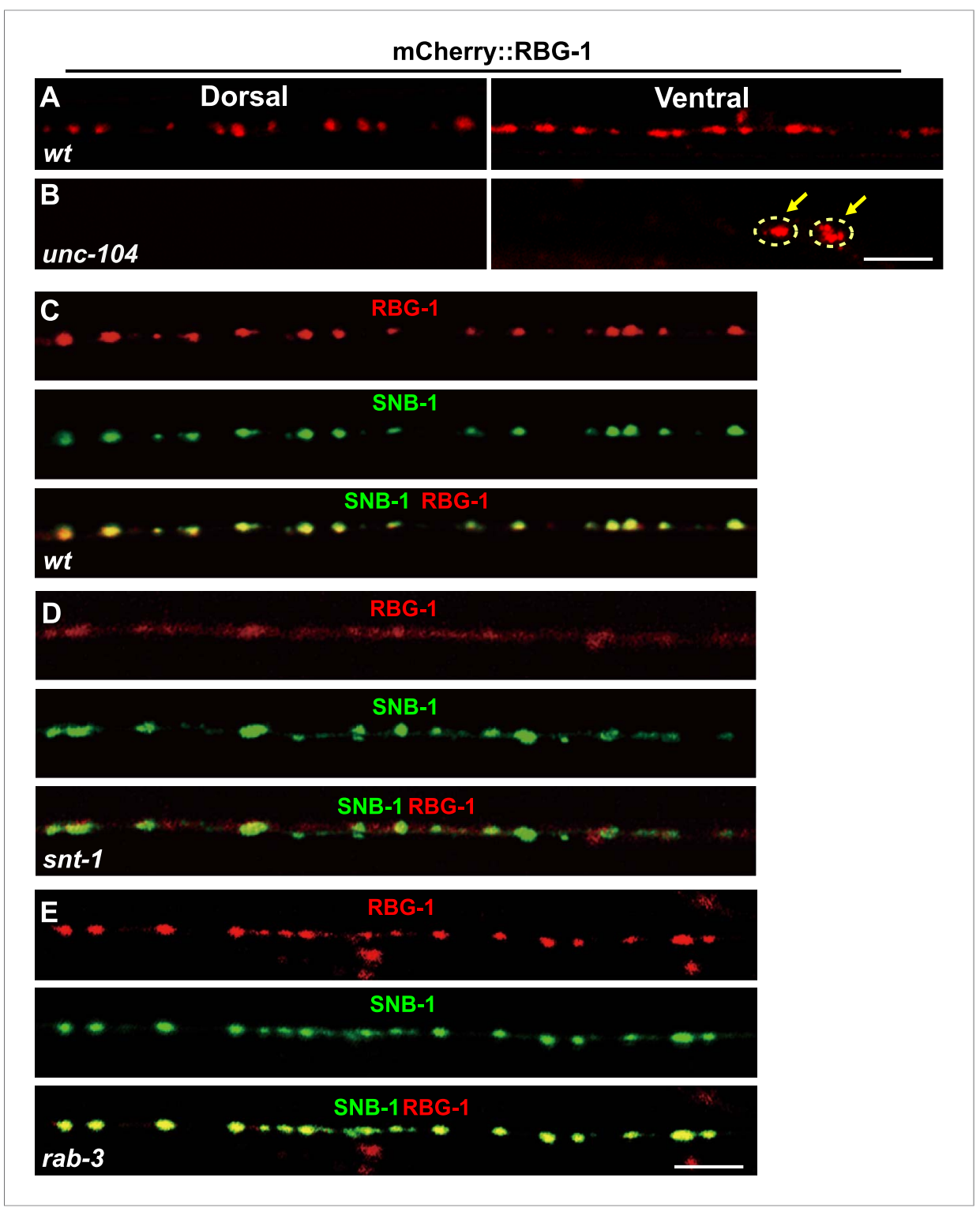

Figure 5. Localization of RBG-1 on synaptic vesicles requires SNT-1. (A and B) mCherry::RBG-1 has a punctate distribution in wild type (A) but accumulates in cell bodies (yellow arrows) in unc-104 mutants (B). (C) mCherry::RBG-1 (red) is co-localized with SNB-1::GFP puncta (green). (D) In snt-1 mutants, mCherry::RBG-1 loses its punctate localization and becomes diffuse in axons, while SNB-1::GFP retains its punctate pattern. (E) mCherry::RBG-1 retains its punctate distribution and is co-localized with SNB-1::GFP in rab-3 mutants. Scale bars, $5 \mu \mathrm{m}$. DOI: 10.7554/eLife.05118.009

mutant animals. In wild-type animals, the mCherry::RBG-1 signal displayed a punctate expression pattern along the ventral and dorsal cords. Double staining further showed that the mCherry::RBG-1 puncta co-localized with the SV marker SNB-1::GFP (Figure 5C). Next, we tested whether the punctate localization of RBG-1 relies on the UNC-104-based intracellular transport system like other SV-associated proteins. We found that in unc-104 mutants, the mCherry::RBG-1 puncta no longer appeared in the putative synaptic region; instead they were retained in the cell bodies (Figure 5B). Together, the data above suggest that RBG-1 is localized on SVs.

\section{SNT-1 is required for the SV localization of RBG-1}

SNT-1 resides on SVs and its function in RAB-3 localization is executed by RAB-3 GAP. Could the SV localization of RBG-1 be regulated by snt-1? We examined RBG-1 distribution in snt-1 animals and found that the RBG-1/SV co-localization is lost and mCherry::RBG-1 fluorescence becomes diffuse 


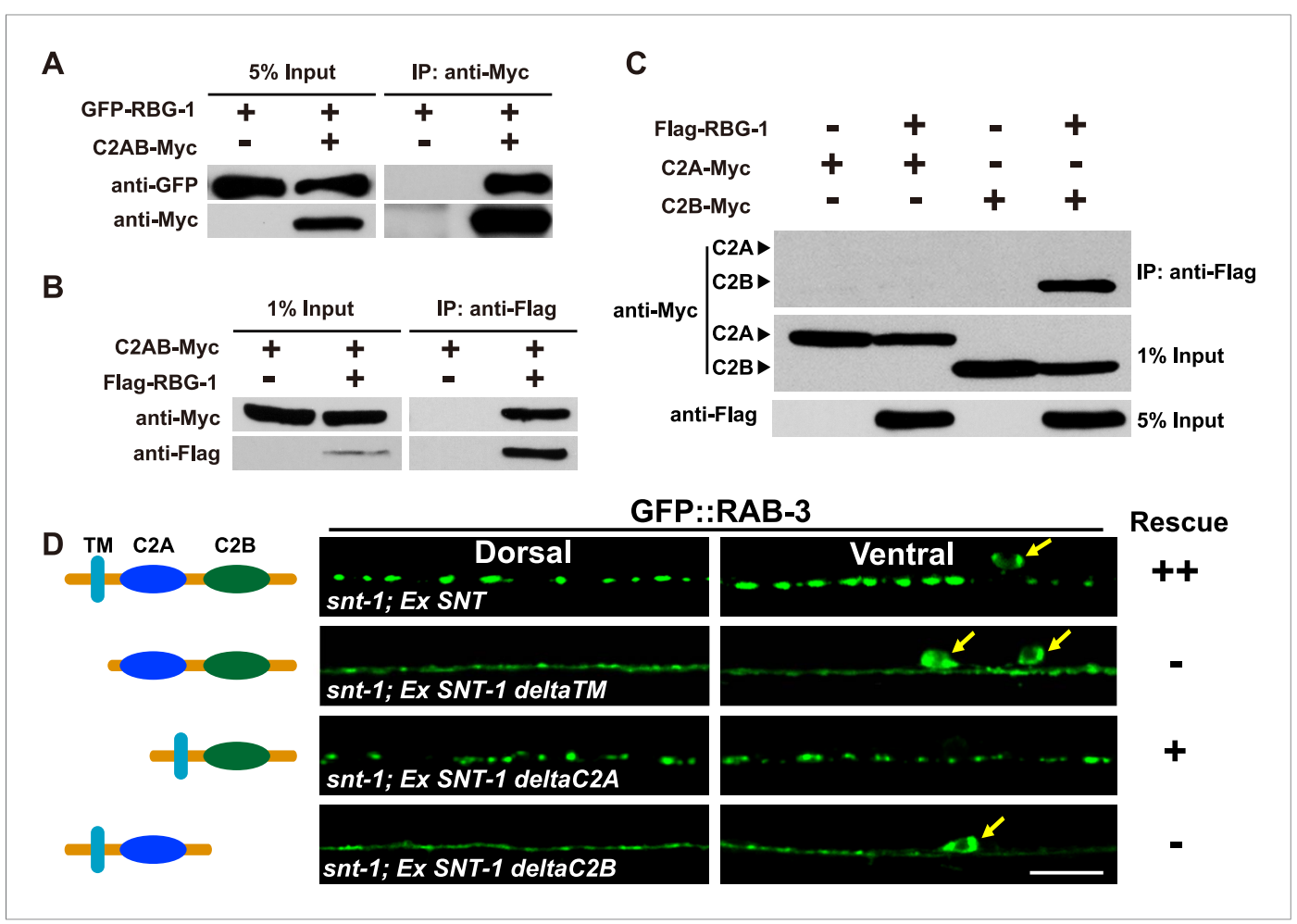

Figure 6. RBG-1 associates with the $\mathrm{C} 2 \mathrm{~B}$ domain of SNT-1. (A) RBG-1 is precipitated by the intracellular domain (C2AB) of SNT-1. (B) The SNT-1 intracellular domain is precipitated by RBG-1. (C) The C2B domain of SNT-1 binds to RBG-1. (D) SNT-1 without the C2B domain fails to rescue the snt-1 mutant phenotype. Yellow arrows indicate cell bodies. The schematic diagram shows the transmembrane (TM) and intracellular calcium-binding domains (C2A and C2B) of SNT-1. Scale bar, $5 \mu \mathrm{m}$.

DOI: 10.7554/eLife.05118.010

(Figure 5D). In contrast, SNB-1::GFP still retains its punctate expression pattern in snt-1 animals, similar to wild type (Figure 5D). Therefore, SNT-1 is required for the SV localization of RBG-1.

RBG-1 binds to its substrate RAB-3 (Figure 4-figure supplement 1E). Thus, we also tested whether the SV localization of RBG-1 is controlled by RAB-3. In rab-3(js49) mutants, we found that mCherry::RBG-1 retains its punctate expression and still co-localizes with SNB-1::GFP (Figure 5E), suggesting that the SV localization of RBG-1 does not rely on RAB-3 protein.

\section{Rab3GAP1/RBG-1 binds to the C2B domain of SNT-1}

The SNT-1-dependent SV association of RBG-1 suggests a direct association between SNT-1 and RBG-1. We co-expressed full-length RBG-1 and the cytosolic domain of SNT-1 (C2AB) in HEK293FT cells. After affinity purification, the RBG-1 protein was incubated with the SNT-1 C2AB fragment. In contrast to the mock-transfected sample, RBG-1 was effectively co-precipitated with the cytosolic region of SNT-1 (Figure 6A). The SNT-1 cytosolic portion was also co-precipitated by RBG-1 (Figure 6B). We next asked which domain of the SNT-1 cytosolic region is required for this binding. The cytosolic region of SNT-1 contains a $\mathrm{C} 2 \mathrm{~A}$ and a $\mathrm{C} 2 \mathrm{~B}$ motif. When the $\mathrm{C} 2 \mathrm{~A}$ domain was deleted, the remaining $\mathrm{C} 2 \mathrm{~B}$ motif retained the RBG-1 binding activity (Figure 6 C). In contrast, when C2B was removed, the C2A domain alone could not bind to RBG-1 (Figure 6 C). Therefore, the C2B domain is required for SNT-1 binding to RBG-1.

We further investigated whether the function of SNT-1 in regulating the RAB-3/SV association is mediated through the $\mathrm{C} 2 \mathrm{~B}$ domain. In comparison with full-length SNT-1, which fully rescues the GFP::RAB-3 mis-localization defect in snt-1 mutants, we found that SNT-1 without the C2B domain (deltaC2B) had no rescue effect (Figure 6D). In contrast, when the C2A domain is removed (deltaC2A) from SNT-1, the remaining protein still possesses the rescue activity (Figure 6D). Together, these data suggest that the C2B domain is critical for SNT-1 function. SNT-1 lacking the trans-membrane domain (deltaTM) also failed to rescue the diffuse RAB-3 phenotype (Figure 6D), suggesting that the SV 
localization function of SNT-1 is required in addition to the C2B domain for regulating RAB-3/SV association in vivo.

\section{$\mathrm{Ca}^{2+}$ treatment decreases the binding between SNT-1 and Rab3GAP1/RBG-1}

$\mathrm{Ca}^{2+}$-mediated exocytosis activates the dissociation of Rab3 from the SV membrane (Fischer von Mollard et al., 1991; Fischer von Mollard et al., 1994). Could synaptotagmin 1, as the $\mathrm{Ca}^{2+}$ sensor for SV exocytosis, be the trigger to initiate the Rab3 SV dissociation process? We showed above that SNT-1 directly associates with Rab3GAP1/RBG-1. Therefore, we wondered whether the $\mathrm{Ca}^{2+}$ level could affect the binding of SNT-1 to RabGAP1/RBG-1, and whether the inhibition of RAB-3 GAP by SNT-1 is relieved by $\mathrm{Ca}^{2+}$ binding, thus allowing dissociation of RAB-3 from the SV during exocytosis. To test the ideas above, we asked whether the presence of $\mathrm{Ca}^{2+}$ disrupts the binding between SNT-1 and RBG-1. We purified RBG-1 and SNT-1 proteins and performed co-IP experiments with increasing concentrations of $\mathrm{Ca}^{2+}$. $\mathrm{A} \mathrm{Ca}^{2+}$ concentration of $0.5 \mathrm{mM}$ or $1 \mathrm{mM}$ significantly compromised the RBG-1/SNT-1interaction (Figure 7A,B). Thus, upon $\mathrm{Ca}^{2+}$ binding, SNT-1 releases RBG-1.

Next, we asked whether SNT-1-RBG-1 binding is still affected by $\mathrm{Ca}^{2+}$ treatment if the $\mathrm{Ca}^{2+}$ -binding sites are removed from SNT-1. The amino acids critical for $\mathrm{Ca}^{2+}$ binding in the C2A domain (D248 and D250) and the C2B domain (D383 and D385) were mutated, and the resulting SNT-1 mutant protein $\left(C 2 A^{\star} B^{\star}\right)$ was purified and tested for its ability to bind RBG-1. We found that the RBG-1-binding capability of $C 2 A^{*} B^{*}$ was high in the absence or presence of $\mathrm{Ca}^{2+}$ (Figure $7 C, D$ ), suggesting that the $\mathrm{Ca}^{2+}$-binding activity of SNT-1 is essential for attenuation of the SNT-1/RBG-1 interaction when $\mathrm{Ca}^{2+}$ is present.

\section{Dissociation of RAB-3 from SVs relies on the $\mathrm{Ca}^{2+}$-binding activity of SNT-1}

$\mathrm{Ca}^{2+}$ treatment decreases the binding between SNT-1 and RBG-1. Is the inhibition of RAB-3 GAP by SNT-1 alleviated when the $\mathrm{Ca}^{2+}$ concentration rises? If so, SNT-1 that lacks $\mathrm{Ca}^{2+}$-binding capability will fail to release RAB-3 GAP during $\mathrm{Ca}^{2+}$ influx, and thus the dissociation of RAB-3 from SVs will be inhibited. To test this hypothesis, we analyzed the GFP::RAB-3 pattern in transgenic animals that express different mutant forms of SNT-1. The two amino acids necessary for $\mathrm{Ca}^{2+}$ binding in the C2A domain of SNT-1 are D248 and D250. We created the SNT-1 mutant C2A* by replacing these two aspartic acids with alanines and found that C2A* could rescue the GFP::RAB-3 mis-localization defect (Figure 7E). In addition to this rescue phenomenon, we noticed that the GFP::RAB-3 puncta were enlarged and the GFP signal was more enriched in the punctate regions in comparison to wild-type animals over-expressing snt-1 (Figure 7E,F). A similar GFP::RAB-3 enrichment effect was observed in worms expressing the $\mathrm{C}^{2} \mathrm{~B}^{*}$ mutant form of SNT-1, which contains a C2B domain that cannot bind $\mathrm{Ca}^{2+}$ (D383 and D385 were replaced with alanines) (Figure 7E,F). We further replaced the $\mathrm{Ca}^{2+}$-binding sites in both $C 2 A$ and $C 2 B\left(C 2 A^{\star} B^{\star}\right)$. When this construct was expressed, the GFP:: $\mathrm{RAB}-3$ signal was also increased in the punctate regions (Figure 7E,F).

Could the enhanced GFP:RAB-3 signal in the puncta indeed reflect the failure of exocytosis? Previous studies suggest that RAB3 dissociation from SV membranes is inhibited when SV exocytosis is disrupted by blocking either $\mathrm{Ca}^{2+}$ influx or membrane fusion (Fischer von Mollard et al., 1991; Fischer von Mollard et al., 1994; Stahl et al., 1996). We examined two exocytosis mutants, unc-2 and unc-13. unc-2 encodes the alpha subunit of the voltage-gated $\mathrm{Ca}^{2+}$ channel (Schafer and Kenyon, 1995). In unc-2 mutants, we found that the GFP signal is significantly enriched within the punctate regions and the GFP::RAB-3 puncta are larger and brighter compared to wild type (Figure 7-figure supplement 1A,B). unc-13 encodes the Munc13 homolog in worms and loss of function of unc-13 results in blockage of membrane fusion during SV exocytosis (Aravamudan et al., 1999; Richmond et al., 1999; Varoqueaux et al., 2002). We found that the GFP signal was enhanced in the punctate regions in unc-13 mutants, as in unc-2 mutants (Figure 7-figure supplement 1A,B). Blocking SV exocytosis resulted in failure of RAB-3 to dissociate from SVs; thus the enlarged GFP::RAB-3 puncta indeed indicate the decreased dissociation of RAB-3 protein from SVs. Taken together, the data above indicate that the $\mathrm{Ca}^{2+}$-binding capability is essential for SNT-1 function in mediating the RAB-3 SV dissociation induced by $\mathrm{Ca}^{2+}$-triggered exocytosis.

Interestingly, in unc-13;snt-1 or unc-2;snt-1 double mutants, the RAB-3::GFP signal is diffuse throughout whole neuronal cells (Figure 7-figure supplement 1A,B), as seen in snt-1 single mutants. 


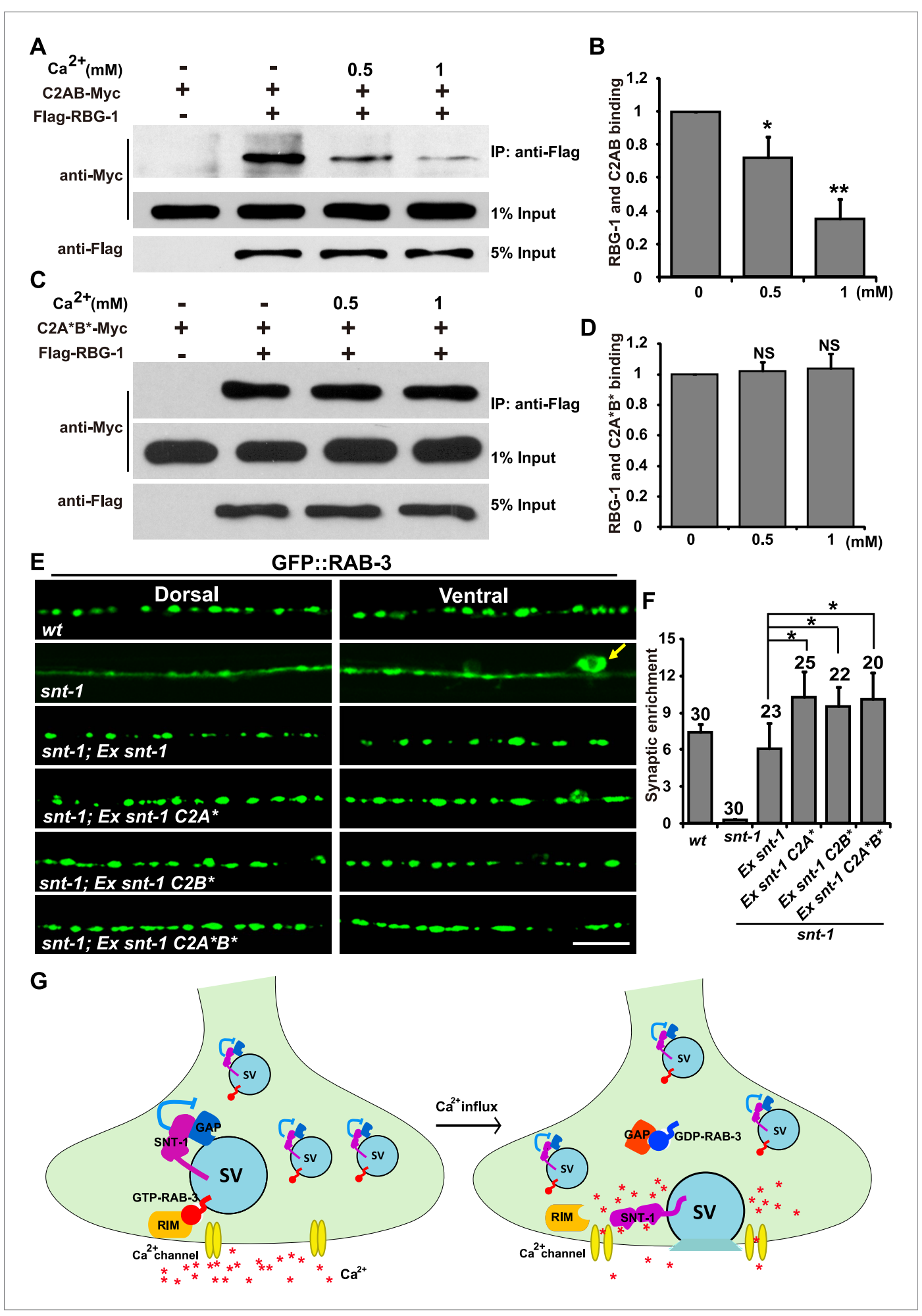

Figure 7. Dissociation of RAB-3 from synaptic vesicles requires the $\mathrm{Ca}^{2+}$-binding activity of SNT-1. (A) $\mathrm{Ca}^{2+}$ treatment diminishes the binding between RBG-1 and the intracellular domain (C2AB) of SNT-1. (B) Quantification of the relative binding between RBG-1 and the C2AB domain upon $\mathrm{Ca}^{2+}$ treatment. (C) SNT-1 without Ca ${ }^{2+}$-binding sites $\left(C 2 A^{*} B^{\star}\right)$ still binds to RBG-1 in the presence of $\mathrm{Ca}^{2+}$. (D) Quantification of the relative binding between RBG-1 and the $C 2 A^{*} B^{*}$ domain upon $\mathrm{Ca}^{2+}$ treatment. (E) Mutant SNT-1 proteins without $\mathrm{Ca}^{2+}$-binding activity stabilize RAB-3 on SVs. Ex snt-1, over-expression of SNT-1; Ex snt-1 C2A* and Ex snt-1 C2B*, over-expression of SNT-1 with mutant C2A domain or $\mathrm{C} 2 \mathrm{~B}$ domain, respectively; Ex snt-1 C2A* $B^{\star}$, over-expression of SNT-1 with mutant C2A and C2B Figure 7. continued on next page 
Figure 7. Continued

domains. Scale bar, $5 \mu \mathrm{m}$. (F) Quantification of the synaptic enrichment in the genotypes shown in (E). (G) SNT-1 functions as a molecular switch controlling RAB-3/SV association and disassociation during SV exocytosis. Data are represented as mean $\pm \mathrm{SD}$. ${ }^{\star} \mathrm{p}<0.05 ;{ }^{\star \star} \mathrm{p}<0.01 ; \mathrm{NS}$, not significant.

DOI: 10.7554/eLife.05118.011

The following figure supplement is available for figure 7 :

Figure supplement 1. Exocytosis is uncoupled from RAB-3 synaptic vesicle dissociation in snt-1 mutants. DOI: 10.7554/eLife.05118.012

Because the diffuse RAB-3::GFP signal suggests a dissociation of RAB-3 from SV membranes, the above observation implies that in the absence of SNT-1, the dissociation of RAB-3 from SVs can occur even when $\mathrm{Ca}^{2+}$-induced exocytosis is blocked. As a consequence, the coupling between SV exocytosis and RAB-3 dissociation is disrupted when SNT-1 is missing. These data are consistent with the inhibition-ofinhibition role of SNT-1 on RAB-3/SV association. Together, these results suggest that SNT-1 plays a dual role in the RAB-3/SV cycle, inhibiting dissociation of RAB-3 from SVs during the resting state (no $\mathrm{Ca}^{2+}$ influx) and triggering dissociation of RAB-3 from SVs upon $\mathrm{Ca}^{2+}$ binding (Figure 7G).

\section{Discussion}

Acute and precise neuronal activity requires precise coordination between the SV cycle and the Rab3 cycle. As the trigger of regulated vesicle secretion, synaptotagmin 1 is known to bind the membrane and the SNARE complex to give the final push for complete assembly of the SNARE complex for membrane fusion (Davletov and Südhof, 1993; Chapman and Davis, 1998; Dai et al., 2007; Choi et al., 2010; Vrljic et al., 2010). Here, we revealed that SNT-1/synaptotagmin 1 functions as an onand-off switch to regulate Rab3 membrane association, thus facilitating repeated release. Our study has many important implications.

In the resting state, Rab3 protein is associated with SVs in the GTP-bound form, and Rab3 GTP, together with its corresponding effectors, docks the vesicles at the active zone region (Sudhof, 2004). However, Rab3 GAP, the negative regulator of Rab3, is also enriched in the synaptic fraction and is localized on SVs (this study) (Oishi et al., 1998). How therefore is the active form of Rab3, and hence the proper docking complex, maintained when GAP is close by? Based upon our study, it is entirely possible that synaptotagmin 1 prevents the hydrolysis of Rab3 GTP by directly sequestering or inhibiting Rab3 GAP before $\mathrm{Ca}^{2+}$ influx. In fact, the SV localization of Rab3GAP1/RBG-1 is particularly interesting, given the fact that the Rab3 cycle must be spatially regulated so that Rab3 is kept in close proximity to SVs for repeated neurotransmitter release. Indeed, when synaptotagmin $1 / \mathrm{SNT}-1$ binds $\mathrm{Ca}^{2+}$, the inhibition on RAB-3 GAP is alleviated, so the locally enriched Rab3 GAP can freely and quickly access GTP-Rab3 and hydrolyze Rab3 GTP to GDP. Together with the functional $\mathrm{Ca}^{2+}$ switch, synaptotagmin 1 can therefore efficiently coordinate the Rab3 cycle with the SV cycle. The concentration of $\mathrm{Ca}^{2+}$ needed for exocytosis ranges from $\sim 10$ to $200 \mu \mathrm{M}$ in the nerve terminals, so the $\mathrm{Ca}^{2+}$ concentration that is required to release RBG-1 from SNT-1 is relatively high $(500 \mu \mathrm{M})$. However, it is known that the rather low affinity of synaptotagmin 1 for $\mathrm{Ca}^{2+}$ (Ubach et al., 1998; Fernandez et al., 2001) can be strongly affected by the presence of synaptotagmin-binding partners, especially membrane lipids (Chapman, 2002). Therefore, it will be interesting to test whether plasma membrane-enriched lipids such as PIP2 (Lee et al., 2010) can act synergistically with $\mathrm{Ca}^{2+}$ to regulate the binding of SNT-1 to RBG-1.

At the molecular level, synaptotagmin 1 is known to bind the plasma membrane and the SNARE complex in the presence of $\mathrm{Ca}^{2+}$ (Davletov and Südhof, 1993; Chapman and Davis, 1998; Fernandez et al., 2001; Dai et al., 2007; Choi et al., 2010; Vrljic et al., 2010). The interaction of synaptotagmin with membranes and SNARE proteins has well-documented consequences, including creating local positive membrane curvature and displacing the clamping factor complexin from the SNARE complex (Martens et al., 2007; Hui et al., 2009). Combining these previous reports with data presented in this study, we think that synaptotagmin- $\mathrm{Ca}^{2+}$ may not only give the final push for complete assembly of the SNARE complex for membrane fusion, but also play a role in terminating vesicle docking by indirectly deactivating Rab3, thus facilitating repetitive transmitter release.

Among more than 60 Rabs in humans and mice, Rab3 and Rab27 seem to be specifically involved in stimulated secretion in a variety of secretory cells (Fukuda, 2008, 2013). Synaptotagmins have also evolved specifically to regulate secretion. Interestingly, the regulatory role of SNT-1 on RAB-3 does 
not extend to RAB-27, which is functionally closely related to RAB-3 (Mahoney et al., 2006). Simultaneous knockdown of Rab3 and Rab27 causes secretion defects more severe than single knockdown in worms and PC12 cells (Mahoney et al., 2006; Tsuboi and Fukuda, 2006). Both Rab27 and Rab3 are localized on SVs and can bind to RIM, thereby docking the vesicles (Wang et al., 1997; Fukuda, 2003). Rab3 and Rab27 share the same GEF, which is AEX-3 in worms and DENN/MADD in mammals (Levivier et al., 2001; Coppola et al., 2002; Mahoney et al., 2006). In contrast, Rab3 GAP serves as a specific GAP for Rab3 (Fukui et al., 1997; Nagano et al., 1998; Itoh and Fukuda, 2006). Here, SNT-1 apparently only affects the RAB-3 cycle and this action is mediated by inhibition of the Rab3-specific GAP. Therefore, although Rab3 and Rab27 play redundant roles in SV exocytosis, they can be differentially controlled through their specific regulators. We would like to point out that humans and worms have multiple synaptotagmins, and it remains to be determined whether any of the other synaptotagmins play a similar regulatory role on Rab27.

Rab3 GAP consists of the catalytic subunit Rab3GAP1 and the noncatalytic subunit Rab3GAP2 (Fukui et al., 1997; Nagano et al., 1998). Rab3GAP1 and Rab3GAP2 form a complex in vitro and coimmunoprecipitate in vivo (Nagano et al., 1998). Although Rab3GAP2 does not affect the in vitro GAP activity of Rab GAP1, it may act to stabilize, regulate, or localize Rab3GAP1 correctly in cells. The functional characteristics are consistent with their close biochemical interactions. Loss-of-function mutations in Rab3GAP1 and Rab3GAP2 produce clinically almost indistinguishable conditions, Warburg Micro syndrome and Martsolf syndrome, characterized by brain, eye, and endocrine abnormalities (Aligianis et alı, 2005, 2006). We have now revealed that both Rab3GAP1/rbg-1 and Rab3GAP1/rbg-2 mutations can suppress the RAB-3 mis-localization phenotype in snt-1 mutants, implying that Rab3GAP does indeed function as a complex to participate in the SNT-1-mediated regulation of the RAB-3 cycle. However, we noticed that loss of function of rbg-2 alone leads to additional synaptic or axonal defects (data not shown) compared to loss of rab-3 or rbg-1. This suggests that RBG-2 may play roles in nervous system development other than forming the Rab3GAP complex with RBG-1 during SV exocytosis.

The GTP-bound active form of Rab promotes membrane trafficking by interacting with specific effectors. In contrast with Rab effectors that function in secretory vesicle trafficking, relatively little is known about the specific Rab GEFs and GAPs and how they are regulated during vesicle secretion. Evidence that the sub-cellular localization and activity of RAB-3 GAP can be regulated by synaptotagmin/SNT-1 strongly hints that regulators of Rabs could be subjects for active manipulation during various types of intracellular membrane trafficking. A recent intriguing study is in agreement with our notion. In the amoeba Dictyostelium discoideum, vacuolar $\mathrm{Ca}^{2+}$ release activates the Rab GAP CnrF, thus subsequently down-regulating Rab11a (Donato et al., 2013). Taken together, current data suggest a vital role of $\mathrm{Ca}^{2+}$ as the functional switch for regulated secretion processes. Because the key principles and regulatory components of different intracellular vesicle trafficking events are broadly conserved, the mechanism that we have uncovered is likely to represent a conserved mode of action.

Understanding how the sequential activation of Rab GTPases is achieved during vesicle trafficking is a central theme of cell biology. This in turn raises the question of how regulatory Rab GEFs or Rab GAPs are activated in the right place and at the right time. Synaptotagmins act as the primary $\mathrm{Ca}^{2+}$-sensors in most forms of $\mathrm{Ca}^{2+}$-induced exocytosis, as exemplified by synaptic transmission. Our studies have proposed the elegant molecular machinery by which Rab GAP can be temporally and spatially regulated in response to acute cellular signals, so that correctly activated Rabs can perform their appropriate functions and allow vesicle fusion to occur in an orderly fashion.

\section{Materials and methods}

\section{Worm strains and mutagenesis}

Strain maintenance and genetic manipulations were performed as described (Brenner, 1974). Strains used in this study are: LG I: EG2710 [unc-57(ok310)], CB450 [unc-13(e450)], VC2481 [rbg-2(ok3195)], CB47 [unc-11(e47)]. LGII: NM204 [snt-1(md290)], CB1265 [unc-104(e1265)], MT6977 [snt-1(n2665)], RM1606 [snt-1(md172)], RM1603 [snt-1(md125)], RM1620 [snt-1(md220)], NM791 [rab-3(js49)]. LGIII: XD1366 [rep-1(xd56)], NM1278 [rbf-1(js232)]. LGIV: EG3027 [unc-26(s1710)], CB169 [unc-31(e169)]. LGV: XD1925 [hmgs-1(xd145)], CB268 [unc-41 (e268)], NM467 [snb-1(md247)], RM956 [ric-4 (md1088)]. LGX: XD1199 [aex-3(xd58)], RB1453 [rbg-1(ok1660)], CB81 [unc-18(e81)], CB55 [unc-2 (e55)], CB102 [unc-10(e102)], CX51 [dyn-1(ky51)]. Additional strains are: XD2188 [xdEx1380; Paex-3:: 
AEX-3::GFP], XD2702 [xdEx1214; Punc-25::mCHERRY::RBG-1], XD3132 [xdEx1461; Phmr-1b::SNT1FL], XD3017 [xdEx1419; Phmr-1b::SNT-1 deltaTM], XD3134 [xdEx1463; Phmr-1b::SNT-1 deltaC2A], XD3034 [xdEx1398; Phmr-1b::SNT-1 deltaC2B], XD3032 [xdEx1396; Phmr-1b::SNT-1 C2A*], XD3033 [xdEx1397; Phmr-1b::SNT-1C2B*], XD3133 [xdEx1462; Phmr-1b::SNT-1C2A*B*]. Mutagenesis was carried out in the $x d l s 7$ (Phmr-1b::GFP::RAB-3) strain treated with ethylmethane sulfonate. From 5000 genomes, 13 mutations were isolated. Subsequent genetic and molecular analysis revealed that we had isolated four alleles of rep-1(xd56, xd138, xd139, and $x d 142)$, six alleles of aex-3(xd58, xd60, $x d 137, x d 143, x d 148$, and $x d 149)$, and three alleles of hmgs-1(xd128, xd129, and xd145). rep-1 (xd138), rep-1(xd139), hmgs-1(xd128) and hmgs-1(xd129) animals are larval lethal. The rest of the identified mutants are fertile.

\section{DNA constructs and transgenic animals}

Promoters, GFP, mCherry, and various cDNA or genomic DNA fragments were cloned into the deltapSM vector through standard procedures. Site-directed mutagenesis was performed using standard PCR-based methods. Transgenic animals were produced as previously described (Song et al., 2010). Integrated strains were obtained by UV irradiation. All integrated transgenic animals were out-crossed at least 3 times.

\section{GTP-RAB-3 pull-down assay}

DNA fragments containing the RBD domains of rat RIM2 were inserted into the pGEX-4T-3 vector. Expression and purification of GST fusion proteins in E. coli were carried out according to standard procedures. Worms with different genotypes were collected and washed in M9 buffer. $800 \mu$ of homogenizing buffer (50 mM Tris- $\mathrm{Cl}$ pH8.0, $\mathrm{NaCl} 150 \mathrm{mM}, 0.5 \%$ sodium deoxycholate, $1 \%$ Triton- $\mathrm{X} 100)$ was added and samples were disrupted with a Dounce homogenizer (Cheng-He Company, Zhuhai, China) (Chen et al., 2010) on ice for $5 \mathrm{~min}$. Debris was removed by centrifuging at 12,000 rpm for $10 \mathrm{~min}$ at $4^{\circ} \mathrm{C}$. The amount of GFP-RAB-3 input in each experiment was equalized before the pulldown assay. The worm lysates were incubated for $4 \mathrm{hr}$ at $4^{\circ} \mathrm{C}$ with GST-tagged RBD RIM2 coupled to glutathione-Sepharose 4B (GE Healthcare, USA). After washing three times, the GFP-RAB-3 level was analyzed by $10 \%$ SDS-PAGE followed by standard western blotting with an anti-GFP antibody (1:5000 dilution) (Santa Cruz Biotechnology).

\section{Co-immunoprecipitation}

To express proteins in HEK293FT cells, cDNA fragments were amplified and cloned into modified pcDNA $^{\mathrm{TM}_{3}}$.1/myc-HIS(-) or pFLAG-CMV-2 vectors through standard procedures. HET293FT cells were cultured in DMEM medium supplemented with $12 \%$ FBS. Plasmid transfections were carried out using Lipofectamine 2000 (Invitrogen, USA). 24 hours after transfection, cells were harvested and lysed for $10 \mathrm{~min}$ at $4^{\circ} \mathrm{C}$. After centrifugation, the supernatants were incubated with anti-FLAG or anti-myc beads at $4^{\circ} \mathrm{C}$ for $4 \mathrm{hr}$. Samples were resolved by standard immunoblotting techniques. For co-immunoprecipitation experiments with purified proteins, the immunoprecipitated samples were eluted with elution buffer (Thermal Scientific, USA) and neutralized with Tris buffer ( $\mathrm{pH}$ 9.0). For GFP-tagged proteins, anti-GFP antibody (Abcam, USA) was incubated with the protein supernatant.

\section{Cell fractionation}

Worms with different genotypes were collected and washed in M9 buffer. $500 \mu$ l of lysis buffer (250 mM sucrose, $50 \mathrm{mM}$ Tris-HCl with pH6.8, $1 \mathrm{mM}$ EDTA) were added and worm samples were homogenized with a Dounce homogenizer (Cheng-He Company, Zhuhai, China) (Chen et al., 2010) on ice for $15 \mathrm{~min}$. The nuclear pellet was removed by centrifuging at $3000 \mathrm{rpm}$ for $10 \mathrm{~min}$ at $4^{\circ} \mathrm{C}$. The supernatant was further centrifuged at 40,000 rpm for $1 \mathrm{hr}$. The new supernatant was collected as the cytosolic fraction. The pellet was further washed and centrifuged at $40,000 \mathrm{rpm}$ for $45 \mathrm{~min}$. All samples were mixed with 2xSDS loading buffer before $10 \%$ SDS-PAGE gel analysis. The GFP-RAB-3 and tubulin levels in each fraction were analyzed by standard western blotting procedures.

\section{Microscopy and image analysis}

Images were captured using a Plan-Apochromat 40X/1.4 objective on an Olympus confocal microscope. All images were taken at the young adult stage unless specifically indicated. Images were analyzed with custom Image J software. Two main parameters were determined: puncta number (PN) and synaptic 
enrichment (SE) (Ch'ng et al., 2008). These were calculated from the punctal fluorescence (PF), which measures the signal intensity at the pre-synaptic specialization, and the inter-punctal fluorescence (IPF), which measures the signal intensity in axons between synapses. An individual punctum is defined when the peak PF/average peak IPF is $\geq 2$. Synaptic enrichment is defined as total PF/total IPF within a $100-\mu \mathrm{m}$ length of middle dorsal cord region. All data are shown as mean \pm SD. Statistical analyses were performed with Student's t-test. For each genotype, more than 20 animals were imaged and analyzed.

\section{Acknowledgments}

We thank Dr Eric Jorgensen, Dr James Rand, Dr Yishi Jin, Dr Xiaochen Wang, Dr Jianyuan Sun, Dr Yuji Kohara, the C. elegans Gene Knockout Consortium, the TransgeneOme Project, and the Caenorhabditis Genetics Center for providing reagents, strains, and technical support. We thank Dr Zhaohui Wang for help with confocal imaging. This work was supported by the National Natural Science Foundation of China (31130023, 31222026, and 31490593), and grants from the National Basic Research Program of China (Y121044691), and the Chinese Academy of Sciences (KSCX-EW-R-05).

\section{Additional information}

Funding

\begin{tabular}{lll} 
Funder & Grant reference & Author \\
\hline $\begin{array}{l}\text { National Natural Science } \\
\text { Foundation of China (NSFC) }\end{array}$ & 31130023 & Mei Ding \\
\hline $\begin{array}{l}\text { Ministry of Science and } \\
\text { Technology, Taiwan }\end{array}$ & $\begin{array}{l}\text { National Basic Research Program } \\
\text { of China Y121044691 }\end{array}$ & Mei Ding \\
\hline $\begin{array}{l}\text { Chinese Academy of Sciences } \\
\text { (CAS) }\end{array}$ & KSCX-EW-R-o5 & Mei Ding \\
\hline $\begin{array}{l}\text { National Natural Science } \\
\text { Foundation of China (NSFC) }\end{array}$ & 31222026 & Mei Ding \\
\hline $\begin{array}{l}\text { National Natural Science } \\
\text { Foundation of China (NSFC) }\end{array}$ & 31490593 & Mei Ding \\
\hline
\end{tabular}

The funders had no role in study design, data collection and interpretation, or the decision to submit the work for publication.

Author contributions

YC, Conception and design, Acquisition of data, Analysis and interpretation of data; JW, Acquisition of data, Analysis and interpretation of data; YW, Acquisition of data, Contributed unpublished essential data or reagents; MD, Conception and design, Drafting or revising the article

\section{References}

Aligianis IA, Johnson CA, Gissen P, Chen D, Hampshire D, Hoffmann K, Maina EN, Morgan NV, Tee L, Morton J, Ainsworth JR, Horn D, Rosser E, Cole TR, Stolte-Dijkstra I, Fieggen K, Clayton-Smith J, Mégarbané A, Shield JP, Newbury-Ecob R, Dobyns WB, Graham JM Jr, Kjaer KW, Warburg M, Bond J, Trembath RC, Harris LW, Takai Y, Mundlos S, Tannahill D, Woods CG, Maher ER. 2005. Mutations of the catalytic subunit of RAB3GAP cause Warburg Micro syndrome. Nature Genetics 37:221-223. doi: 10.1038/ng1517.

Aligianis IA, Morgan NV, Mione M, Johnson CA, Rosser E, Hennekam RC, Adams G, Trembath RC, Pilz DT, Stoodley N, Moore AT, Wilson S, Maher ER. 2006. Mutation in Rab3 GTPase-activating protein (RAB3GAP) noncatalytic subunit in a kindred with Martsolf syndrome. American Journal of Human Genetics 78:702-707. doi: $10.1086 / 502681$

Andres DA, Seabra MC, Brown MS, Armstrong SA, Smeland TE, Cremers FP, Goldstein JL. 1993. cDNA cloning of component A of Rab geranylgeranyl transferase and demonstration of its role as a Rab escort protein. Cell 73: 1091-1099. doi: 10.1016/0092-8674(93)90639-8.

Aravamudan B, Fergestad T, Davis WS, Rodesch CK, Broadie K. 1999. Drosophila UNC-13 is essential for synaptic transmission. Nature Neuroscience 2:965-971. doi: 10.1038/14764.

Brenner S. 1974. The genetics of Caenorhabditis elegans. Genetics 77:71-94.

Brunger AT. 2005. Structure and function of SNARE and SNARE-interacting proteins. Quarterly Reviews of Biophysics 38:1-47. doi: 10.1017/S0033583505004051.

Ch'ng Q, Sieburth D, Kaplan JM. 2008. Profiling synaptic proteins identifies regulators of insulin secretion and lifespan. PLOS Genetics 4:e1000283. doi: 10.1371/journal.pgen.1000283. 
Chapman ER. 2002. Synaptotagmin: a Ca(2+) sensor that triggers exocytosis?Nature Reviews Molecular Cell Biology 3:498-508. doi: 10.1038/nrm855.

Chapman ER, Davis AF. 1998. Direct interaction of a Ca2+-binding loop of synaptotagmin with lipid bilayers. The Journal of Biological Chemistry 273:13995-14001. doi: 10.1074/jbc.273.22.13995.

Chen D, Xiao H, Zhang K, Wang B, Gao Z, Jian Y, Qi X, Sun J, Miao L, Yang C. 2010. Retromer is required for apoptotic cell clearance by phagocytic receptor recycling. Science 327:1261-1264. doi: 10.1126/science. 1184840.

Choi UB, Strop P, Vrljic M, Chu S, Brunger AT, Weninger KR. 2010. Single-molecule FRET-derived model of the synaptotagmin 1-SNARE fusion complex. Nature Structural \& Molecular Biology 17:318-324. doi: 10.1038/nsmb. 1763.

Coppola T, Perret-Menoud V, Gattesco S, Magnin S, Pombo I, Blank U, Regazzi R. 2002. The death domain of Rab3 guanine nucleotide exchange protein in GDP/GTP exchange activity in living cells. The Biochemical Journal 362: 273-279. doi: 10.1042/0264-6021:3620273.

Dai H, Shen N, Arac D, Rizo J. 2007. A quaternary SNARE-synaptotagmin-Ca2+-phospholipid complex in neurotransmitter release. Journal of Molecular Biology 367:848-863. doi: 10.1016/j.jmb.2007.01.040.

Davletov BA, Südhof TC. 1993. A single C2 domain from synaptotagmin I is sufficient for high affinity Ca2+ /phospholipid binding. The Journal of Biological Chemistry 268:26386-26390.

Donato F, Rompani SB, Caroni P. 2013. Parvalbumin-expressing basket-cell network plasticity induced by experience regulates adult learning. Nature 504:272-276. doi: 10.1038/nature12866.

Fernandez I, Arac D, Ubach J, Gerber SH, Shin O, Gao Y, Anderson RG, Sudhof TC, Rizo J. 2001. Threedimensional structure of the synaptotagmin $1 \mathrm{C} 2 \mathrm{~B}$-domain: synaptotagmin 1 as a phospholipid binding machine. Neuron 32:1057-1069. doi: 10.1016/S0896-6273(01)00548-7.

Fischer von Mollard G, Mignery GA, Baumert M, Perin MS, Hanson TJ, Burger PM, Jahn R, Südhof TC. 1990. rab3 is a small GTP-binding protein exclusively localized to synaptic vesicles. Proceedings of the National Academy of Sciences of USA 87:1988-1992. doi: 10.1073/pnas.87.5.1988.

Fischer von Mollard G, Stahl B, Khokhlatchev A, Sudhof TC, Jahn R. 1994. Rab3C is a synaptic vesicle protein that dissociates from synaptic vesicles after stimulation of exocytosis. The Journal of Biological Chemistry 269: 10971-10974.

Fischer von Mollard G, Südhof TC, Jahn R. 1991. A small GTP-binding protein dissociates from synaptic vesicles during exocytosis. Nature 349:79-81. doi: 10.1038/349079a0.

Fukuda M. 2003. Distinct Rab binding specificity of Rim1, Rim2, rabphilin, and Noc2. Identification of a critical determinant of Rab3A/Rab27A recognition by Rim2. The Journal of Biological Chemistry 278:15373-15380. doi: 10.1074/jbc.M212341200.

Fukuda M. 2008. Regulation of secretory vesicle traffic by Rab small GTPases. Cellular and Molecular Life Sciences 65:2801-2813. doi: 10.1007/s00018-008-8351-4.

Fukuda M. 2013. Rab27 effectors, pleiotropic regulators in secretory pathways. Traffic 14:949-963. doi: 10.1111/ tra.12083.

Fukui K, Sasaki T, Imazumi K, Matsuura Y, Nakanishi H, Takai Y. 1997. Isolation and characterization of a GTPase activating protein specific for the Rab3 subfamily of small G proteins. The Journal of Biological Chemistry 272: 4655-4658. doi: 10.1074/jbc.272.8.4655.

Geppert M, Bolshakov VY, Siegelbaum SA, Takei K, De Camilli P, Hammer RE, Südhof TC. 1994. The role of Rab3A in neurotransmitter release. Nature 369:493-497. doi: 10.1038/369493a0.

Geppert M, Südhof TC. 1998. RAB3 and synaptotagmin: the yin and yang of synaptic membrane fusion. Annual Review of Neuroscience 21:75-95. doi: 10.1146/annurev.neuro.21.1.75.

Hall DH, Hedgecock EM. 1991. Kinesin-related gene unc-104 is required for axonal transport of synaptic vesicles in C. elegans. Cell 65:837-847. doi: 10.1016/0092-8674(91)90391-B.

Hui E, Johnson CP, Yao J, Dunning FM, Chapman ER. 2009. Synaptotagmin-mediated bending of the target membrane is a critical step in Ca(2+)-regulated fusion. Cell 138:709-721. doi: 10.1016/j.cell.2009.05.049.

Itoh T, Fukuda M. 2006. Identification of EPI64 as a GTPase-activating protein specific for Rab27A. The Journal of Biological Chemistry 281:31823-31831. doi: 10.1074/jbc.M603808200.

Iwasaki K, Staunton J, Saifee O, Nonet M, Thomas JH. 1997. aex-3 encodes a novel regulator of presynaptic activity in C. elegans. Neuron 18:613-622. doi: 10.1016/S0896-6273(00)80302-5.

Jahn R, Fasshauer D. 2012. Molecular machines governing exocytosis of synaptic vesicles. Nature 490:201-207. doi: 10.1038/nature11320.

Jahn R, Scheller RH. 2006. SNAREs-engines for membrane fusion. Nature Reviews Molecular Cell Biology 7: 631-643. doi: 10.1038/nrm2002.

Lang T, Jahn R. 2008. Core proteins of the secretory machinery. Handbook of Experimental Pharmacology 107-127.

Lee HK, Yang Y, Su Z, Hyeon C, Lee TS, Lee HW, Kweon DH, Shin YK, Yoon TY. 2010. Dynamic Ca2+-dependent stimulation of vesicle fusion by membrane-anchored synaptotagmin 1. Science 328:760-763. doi: 10.1126/ science.1187722.

Leenders AG, Lopes da Silva FH, Ghijsen WE, Verhage M. 2001. Rab3a is involved in transport of synaptic vesicles to the active zone in mouse brain nerve terminals. Molecular Biology of the Cell 12:3095-3102. doi: 10.1091/mbc. 12.10.3095.

Levivier E, Goud B, Souchet M, Calmels TP, Mornon JP, Callebaut I. 2001. uDENN, DENN, and dDENN: indissociable domains in Rab and MAP kinases signaling pathways. Biochemical and Biophysical Research Communications 287:688-695. doi: 10.1006/bbrc.2001.5652. 
Li C, Takei K, Geppert M, Daniell L, Stenius K, Chapman ER, Jahn R, De Camilli P, Südhof TC. 1994. Synaptic targeting of rabphilin-3A, a synaptic vesicle $\mathrm{Ca} 2+$ /phospholipid-binding protein, depends on rab3A/3C. Neuron 13:885-898. doi: 10.1016/0896-6273(94)90254-2.

Mahoney TR, Liu Q, Itoh T, Luo S, Hadwiger G, Vincent R, Wang ZW, Fukuda M, Nonet ML. 2006. Regulation of synaptic transmission by RAB-3 and RAB-27 in Caenorhabditis elegans. Molecular Biology of the Cell 17: 2617-2625. doi: 10.1091/mbc.E05-12-1170.

Martens S, Kozlov MM, McMahon HT. 2007. How synaptotagmin promotes membrane fusion. Science $\mathbf{3 1 6}$ : 1205-1208. doi: 10.1126/science.1142614.

Mehrabian M, Callaway KA, Clarke CF, Tanaka RD, Greenspan M, Lusis AJ, Sparkes RS, Mohandas T, Edmond J, Fogelman AM, Edwards PA. 1986. Regulation of rat liver 3-hydroxy-3-methylglutaryl coenzyme A synthase and the chromosomal localization of the human gene. The Journal of Biological Chemistry 261:16249-16255.

Nagano F, Sasaki T, Fukui K, Asakura T, Imazumi K, Takai Y. 1998. Molecular cloning and characterization of the noncatalytic subunit of the Rab3 subfamily-specific GTPase-activating protein. The Journal of Biological Chemistry 273:24781-24785. doi: 10.1074/jbc.273.38.24781.

Nonet ML. 1999. Visualization of synaptic specializations in live $C$. elegans with synaptic vesicle protein-GFP fusions. Journal of Neuroscience Methods 89:33-40. doi: 10.1016/S0165-0270(99)00031-X.

Nonet ML, Grundahl K, Meyer BJ, Rand JB. 1993. Synaptic function is impaired but not eliminated in C. elegans mutants lacking synaptotagmin. Cell 73:1291-1305. doi: 10.1016/0092-8674(93)90357-V.

Nonet ML, Staunton JE, Kilgard MP, Fergestad T, Hartwieg E, Horvitz HR, Jorgensen EM, Meyer BJ. 1997. Caenorhabditis elegans rab-3 mutant synapses exhibit impaired function and are partially depleted of vesicles. The Journal of Neuroscience 17:8061-8073.

Oishi H, Sasaki T, Nagano F, Ikeda W, Ohya T, Wada M, Ide N, Nakanishi H, Takai Y. 1998. Localization of the Rab3 small $\mathrm{G}$ protein regulators in nerve terminals and their involvement in $\mathrm{Ca} 2+$-dependent exocytosis. The Journal of Biological Chemistry 273:34580-34585. doi: 10.1074/jbc.273.51.34580.

Richmond JE, Davis WS, Jorgensen EM. 1999. UNC-13 is required for synaptic vesicle fusion in C. elegans. Nature Neuroscience 2:959-964. doi: 10.1038/12160.

Schafer WR, Kenyon CJ. 1995. A calcium-channel homologue required for adaptation to dopamine and serotonin in Caenorhabditis elegans. Nature 375:73-78. doi: 10.1038/375073a0.

Seabra MC, Brown MS, Slaughter CA, Sudhof TC, Goldstein JL. 1992a. Purification of component A of Rab geranylgeranyl transferase: possible identity with the choroideremia gene product. Cell 70:1049-1057. doi: 10. 1016/0092-8674(92)90253-9.

Seabra MC, Goldstein JL, Sudhof TC, Brown MS. 1992b. Rab geranylgeranyl transferase. A multisubunit enzyme that prenylates GTP-binding proteins terminating in Cys-X-Cys or Cys-Cys. The Journal of Biological Chemistry 267:14497-14503.

Shi Z, Ruvkun G. 2012. The mevalonate pathway regulates microRNA activity in Caenorhabditis elegans. Proceedings of the National Academy of Sciences of USA 109:4568-4573. doi: 10.1073/pnas.1202421109.

Shirataki H, Kaibuchi K, Sakoda T, Kishida S, Yamaguchi T, Wada K, Miyazaki M, Takai Y. 1993. Rabphilin-3A, a putative target protein for smg p25A/rab3A p25 small GTP-binding protein related to synaptotagmin. Molecular and Cellular Biology 13:2061-2068.

Song S, Zhang B, Sun H, Li X, Xiang Y, Liu Z, Huang X, Ding M. 2010. A Wnt-Frz/Ror-Dsh pathway regulates neurite outgrowth in Caenorhabditis elegans. PLOS Genetics 6:. doi: 10.1371/journal.pgen.1001056.

Stahl B, Chou JH, Li C, Sudhof TC, Jahn R. 1996. Rab3 reversibly recruits rabphilin to synaptic vesicles by a mechanism analogous to raf recruitment by ras. The EMBO Journal 15:1799-1809.

Sudhof TC. 2004. The synaptic vesicle cycle. Annual Review of Neuroscience 27:509-547. doi: 10.1146/annurev. neuro.26.041002.131412.

Sulston JE. 1976. Post-embryonic development in the ventral cord of Caenorhabditis elegans. Philosophical Transactions of the Royal Society of London Series B, Biological Sciences 275:287-297. doi: 10.1098/rstb.1976.0084.

Sulston JE, Horvitz HR. 1977. Post-embryonic cell lineages of the nematode, Caenorhabditis elegans. Developmental Biology 56:110-156. doi: 10.1016/0012-1606(77)90158-0.

Tanaka D, Kameyama K, Okamoto H, Doi M. 2008. Caenorhabditis elegans Rab escort protein (REP-1) differently regulates each Rab protein function and localization in a tissue-dependent manner. Genes to Cells 13: 1141-1157. doi: 10.1111/j.1365-2443.2008.01232.x.

Tsuboi T, Fukuda M. 2006. Rab3A and Rab27A cooperatively regulate the docking step of dense-core vesicle exocytosis in PC12 cells. Journal of Cell Science 119:2196-2203. doi: 10.1242/jcs.02962.

Ubach J, Zhang X, Shao X, Sudhof TC, Rizo J. 1998. Ca2+ binding to synaptotagmin: how many Ca2+ ions bind to the tip of a C2-domain?The EMBO Journal 17:3921-3930. doi: 10.1093/emboj/17.14.3921.

Varoqueaux F, Sigler A, Rhee JS, Brose N, Enk C, Reim K, Rosenmund C. 2002. Total arrest of spontaneous and evoked synaptic transmission but normal synaptogenesis in the absence of Munc13-mediated vesicle priming. Proceedings of the National Academy of Sciences of USA 99:9037-9042. doi: 10.1073/pnas.122623799.

Vrljic M, Strop P, Ernst JA, Sutton RB, Chu S, Brunger AT. 2010. Molecular mechanism of the synaptotagminSNARE interaction in Ca2+-triggered vesicle fusion. Nature Structural \& Molecular Biology 17:325-331. doi: 10. 1038/nsmb.1764.

Wang Y, Okamoto M, Schmitz F, Hofmann K, Sudhof TC. 1997. Rim is a putative Rab3 effector in regulating synaptic-vesicle fusion. Nature 388:593-598. doi: 10.1038/41580.

Wang Y, Sugita S, Sudhof TC. 2000. The RIM/NIM family of neuronal C2 domain proteins. Interactions with Rab3 and a new class of Src homology 3 domain proteins. The Journal of Biological Chemistry 275:20033-20044. doi: 10.1074/jbc.M909008199. 
Weber T, Zemelman BV, McNew JA, Westermann B, Gmachl M, Parlati F, Sollner TH, Rothman JE. 1998. SNAREpins: minimal machinery for membrane fusion. Cell 92:759-772. doi: 10.1016/S0092-8674(00)81404-X. Yu SC, Klosterman SM, Martin AA, Gracheva EO, Richmond JE. 2013. Differential roles for snapin and synaptotagmin in the synaptic vesicle cycle. PLOS ONE 8:e57842. doi: 10.1371/journal.pone.0057842. Zerial M, McBride H. 2001. Rab proteins as membrane organizers. Nature Reviews Molecular cell biology 2: 107-117. doi: 10.1038/35052055.

Zhen M, Jin Y. 1999. The liprin protein SYD-2 regulates the differentiation of presynaptic termini in C. elegans. Nature 401:371-375. 